Article

\title{
Immune Milieu and Genomic Alterations Set the Triple-Negative Breast Cancer Immunomodulatory Subtype Tumor Behavior
}

\author{
Rubén Rodríguez-Bautista ${ }^{1,2}$, Claudia H. Caro-Sánchez ${ }^{3}$, Paula Cabrera-Galeana ${ }^{4}$, Gerardo J. Alanis-Funes ${ }^{5}{ }^{\circ}$, \\ Everardo Gutierrez-Millán ${ }^{6}$, Santiago Ávila-Ríos ${ }^{7}$, Margarita Matías-Florentino ${ }^{7}$, Gustavo Reyes-Terán ${ }^{7}$, \\ José Díaz-Chávez ${ }^{8}$, Cynthia Villarreal-Garza ${ }^{4}, 9$, Norma Y. Hernández-Pedro ${ }^{1}$, Alette Ortega-Gómez ${ }^{10}$, \\ Luis Lara-Mejía ${ }^{11}$, Claudia Rangel-Escareño ${ }^{12,13, *}$ and Oscar Arrieta 1,11,*
}

check for updates

Citation: Rodríguez-Bautista, R.; Caro-Sánchez, C.H.; Cabrera-Galeana,

P.; Alanis-Funes, G.J.;

Gutierrez-Millán, E.; Ávila-Ríos, S.;

Matías-Florentino, M.; Reyes-Terán,

G.; Díaz-Chávez, J.; Villarreal-Garza,

C.; et al. Immune Milieu and

Genomic Alterations Set the

Triple-Negative Breast Cancer

Immunomodulatory Subtype Tumor

Behavior. Cancers 2021, 13, 6256.

https://doi.org/10.3390/

cancers 13246256

Academic Editors: Gustavo A.

Miranda-Carboni, Susan A. Krum and Tiffany N. Seagroves

Received: 19 November 2021 Accepted: 8 December 2021

Published: 13 December 2021

Publisher's Note: MDPI stays neutral with regard to jurisdictional claims in published maps and institutional affiliations.

Copyright: (c) 2021 by the authors. Licensee MDPI, Basel, Switzerland. This article is an open access article distributed under the terms and conditions of the Creative Commons Attribution (CC BY) license (https:/ / creativecommons.org/licenses/by/ $4.0 /)$.
1 Laboratorio de Medicina Personalizada de la Unidad de Oncología Torácica, Instituto Nacional de Cancerología (INCan), Mexico City 14080, Mexico; rubenrb@comunidad.unam.mx (R.R.-B.); nhernandezp@incan.edu.mx (N.Y.H.-P.)

2 Programa de Doctorado en Ciencias Biomédicas, Facultad de Medicina, Universidad Nacional Autónoma de México (UNAM), Mexico City 04510, Mexico

3 Departmento de Patología, Instituto Nacional de Cancerología (INCan), Mexico City 14080, Mexico; ccavos@incan.edu.mx

4 Departamento de Oncología Médica-Tumores Mamarios, Instituto Nacional de Cancerología (INCan), Mexico City 14080, Mexico; pcabrerag@incan.edu.mx (P.C.-G.); cynthia.villarreal@tecsalud.mx (C.V.-G.)

5 Bio Assisted Sequencing Environment National Sequencing Laboratory (Tec-BASE), School of Engineering and Sciences, Tecnologico de Monterrey, Monterrey 64849, Mexico; gerardo.alanisf@tec.mx

6 Centro de Investigación sobre Enfermedades Infecciosas, Instituto Nacional de Salud Pública, Cuernavaca 62100, Mexico; everardo.gutierrez@insp.edu.mx

7 Centro de Investigación de Enfermedades Infecciosas, Instituto Nacional de Enfermedades Respiratorias, Mexico City 14080, Mexico; santiago.avila@cieni.org.mx (S.Á.-R.); margarita.matias@cieni.org.mx (M.M.-F.); gustavo.reyesteran@salud.gob.mx (G.R.-T.)

8 Unidad de Investigación Biomédica en Cáncer, INCan-Instituto de Investigaciones Biomédicas, UNAM, Mexico City14080, Mexico; jdiazchavez03@comunidad.unam.mx

9 Centro de Cáncer de Mama, Hospital Zambrano Hellion, Tecnologico de Monterrey, Monterrey 66278, Mexico

10 Laboratorio de Medicina Traslacional, Instituto Nacional de Cancerología (INCan), Mexico City 14080, Mexico; aortegag@incan.edu.mx

11 Thoracic Oncology Unit, Department of Thoracic Oncology, Instituto Nacional de Cancerología (INCan), Mexico City 14080, Mexico; luis.laram@incmnsz.mx

12 School of Engineering and Sciences, Tecnologico de Monterrey, Epigmenio González 500, San Pablo, Santiago de Querétaro 76130, Mexico

13 Computational Genomics and Integrative Biology, National Institute of Genomic Medicine (INMEGEN), Periférico Sur 4809 Arenal Tepepan, Mexico City 14610, Mexico

* Correspondence: crangel@inmegen.gob.mx (C.R.-E.); ogar@unam.mx (O.A.); Tel.: +52-(55)-5628-0400 (ext. 71100) (O.A.); Fax: +52-(55)-55-131-5122 (O.A.)

Simple Summary: Triple-negative breast cancer (TNBC) is an aggressive and highly heterogeneous breast cancer subtype, both molecular and transcriptomic. Gene expression patterns identified seven TNBC subtypes; basal-like 1 (BL1), basal-like 2 (BL2), immunomodulatory (IM), mesenchymal (M), mesenchymal stem-like (MSL), luminal androgen receptor (LAR), and unstable (UNS). Herein, we contrasted the IM subtype with non-IM TNBC, including clinical, histopathological, and molecular variables. Our results showed that the IM subtype featured an increased FOXP3+ TILs infiltration and a higher CTLA-4 and PD-L1 expression compared with non-IM tumors. Long intergenic noncoding RNAs associated with the immune response through transcriptomic and enrichment analyses characterized the IM-subtype enriched by the $\beta$-catenin signaling pathway. Additionally, DNA sequencing identified differences in mutation rates as well as some specific mutations. These results should motivate the design of future clinical trials in which the benefit of immune-based therapy in this subgroup of patients could be evaluated.

Abstract: Triple-negative breast cancer (TNBC) is an aggressive and heterogeneous disease. Seven subtypes have been described based on gene expression patterns. Herein, we characterized the tumor 
biology and clinical behavior of the immunomodulatory (IM) subtype. Methods: Formalin-fixed paraffin-embedded tumor samples from 68 high-risk (stage III-IV) TNBC patients were analyzed through microarrays, immunohistochemistry, and DNA sequencing. Results: The IM subtype was identified in $24 \%$ of TNBC tumor samples and characterized by a higher intratumoral (intT) and stromal (strml) infiltration of FOXP3+ TILs (Treg) compared with non-IM subtypes. Further, PD-L1+ $(>1 \%)$ expression was significantly higher, as well as CTLA-4+ intT and strml expression in the IM subtype. Differential expression and gene set enrichment analysis identified biological processes associated with the immune system. Pathway analysis revealed enrichment of the $\beta$-catenin signaling pathway. The non-coding analysis led to seven Long Intergenic Non-Protein Coding RNAs (lincRNAs) (6 up-regulated and 1 down-regulated) that were associated with a favorable prognosis in the TNBC-IM subtype. The DNA sequencing highlighted two genes relevant to immune system responses: CTNNB1 (Catenin $\beta-1$ ) and IDH1. Conclusion: the IM subtype showed a distinct immune microenvironment, as well as subtype-specific genomic alterations. Characterizing TNBC at a molecular and transcriptomic level might guide immune-based therapy in this subgroup of patients.

Keywords: immunology; molecular subtype; immune checkpoint inhibitors; programmed deathligand; tumor-infiltrating lymphocytes

\section{Introduction}

Triple-Negative Breast Cancer (TNBC) is a highly aggressive and life-threatening malignancy. It accounts for approximately $10-15 \%$ of breast cancers diagnosed worldwide [1], affecting primarily young women, with a higher prevalence among African-American and Hispanic subgroups [2]. TNBC is characterized as a poor-prognosis malignancy. This subtype lacks the expression of estrogen and progesterone receptors, as well as the overexpression of the HER2 protein. Further, this is a genomically and transcriptomically heterogeneous disease, exhibiting molecular diversity, a higher rate of chromosomal translocations and different gene expression patterns [3]. This intrinsic heterogeneity has motivated the search for subtypes within TNBC. One of the most interesting reports in this regard is the TNBC subtype classifier by Lehmann et al. This study described an intrinsic TNBC subtype characterized by upregulated immune responses, immune cell markers, immune transcription factors, and a predominant dysregulation of immune pathways [4]. Since then, the immunomodulatory (IM) subtype has been proposed for individualized treatment by modulating its immune milieu [5].

Immunotherapy has improved the prognosis of many solid neoplasms [6]. TNBC could also benefit from this type of cancer treatment through a profound understanding of how the immune system regulates the tumor microenvironment, identifying the main components regulated by immunotherapy, such as immune cells surrounding the tumor such as tumor-infiltrating lymphocytes (TIL) [7]. TNBC has already shown intense TILs enhancing tumor responses $[8,9]$. Recent data have demonstrated an upregulation of the tumor-immune system in subjects undergoing chemotherapy by activating CD8+ (Th1) TILs [8], positively correlating with improved responses [10] and even with increased survival [11,12] Similarly, higher CD4-TILs (Th2) have been associated with favorable outcomes [13]. Immune cell subpopulations that predominate in the IM subtype have not been fully addressed as potential factors in the diversity of clinical outcomes [14].

Anti-PD1 (programmed death-1) therapy plus chemotherapy have been incorporated into the therapeutical arsenal of locally advanced, recurrent, or metastatic PD-L1-positive TNBC, showing a progression-free survival benefit in this subgroup of patients [15-17]. More recently, immunotherapy has been introduced in earlier stages, increasing pathological complete responses (pCR) in the neoadjuvant setting [18,19]. PDL-1 has been one of the most, or perhaps the most, studied biomarker in the last decade. However, inconsistencies in its results have affected its reliability [20]. In breast cancer, PD-L1 expression has been 
observed in $20-50 \%$ of tumor cells and TILs [21]. Furthermore, the cytotoxic T lymphocyte antigen 4 (CTLA-4) has been studied in TNBC cells due to its critical functional role in TILs, modulating the immune response [22], although its relevance in clinical terms is limited. Some genomic metrics have been correlated with immune-rich TNBCs, in which a reduced number of somatic copy number alterations, as well as reduced clonal heterogeneity, was inversely associated with an immune metagene expression. Moreover, significantly lower mutations and neoantigen counts were associated with an increased T-lymphocyte infiltration [23]. Nonetheless, the precise determination of which TNBC patient subgroups will benefit from treatment with immune checkpoint inhibitors (ICIs) remains a challenge. Focusing on the intrinsic subtypes might lead to more promising results. This study aimed to characterize the immune milieu through genome alterations, patterns in non-coding regions, gene expression analysis, and the clinical behavior of the TNBC-IM subtype in high-risk clinical stage III and IV TNBC patients.

\section{Materials and Methods}

\subsection{Sample Selection}

Formalin-fixed, paraffin-embedded (FFPE) tissue samples from 68 TNBC patients treated at the Breast Cancer Department in the Instituto Nacional de Cancerología of Mexico (INCan), archived from 2007-2010, were considered eligible for this study. All the samples were confirmed as TNBC, estrogen receptor (ER)-negative, progesterone receptor (PR)-negative, and HER-2-negative by immunohistochemistry assessed according to the $2020 \mathrm{ASCO} / \mathrm{CAP}$ guidelines using an FDA-approved assay [24]. The histologic subtype and grade of differentiation were determined according to the WHO classification and the Nottingham histologic grading system [24]. The INCan institutional review board approved the study (No. INCAN/CI/200/13INCAN/CEI/224/13/CEI/847). All the patients provided informed consent and the procedures were carried out under the terms of the Helsinki Declaration. Patients were excluded if clinicopathological information or material/sample were not available or were incomplete. Before inclusion, hematoxylin and eosin (H\&E)-stained slides from tumor samples were reviewed by one breast pathologist to evaluate the percentage of tumor cells and necrotic areas. If fewer than $60 \%$ tumor cells or $>40 \%$ necrotic area were present on inspection, regions of interest were circled on the H\&E-stained slides. The corresponding areas from unstained FFPE tissue sections were then manually macro-dissected for tumor enrichment.

All the clinicopathological data were extracted from electronic medical records (EMR). The overall survival (OS) was defined as the time from diagnosis until death due to any cause, whereas progression-free survival (PFS) was defined as the time from treatment onset until radiological tumor progression, death, or loss to follow-up.

\subsection{Nucleic Acid Extraction}

Total RNA and DNA were isolated from FFPE tissue sections using the AllPrep DNA/RNA FFPE Kit by Qiagen (Hilden, Germany). Paraffin sections were placed in sterile $1.5 \mathrm{~mL}$ microcentrifuge tubes, deparaffinized with $100 \%$ xylene, and washed twice in $100 \%$ ethanol. Deparaffinized tissue was digested with proteinase $\mathrm{K}$ at $56^{\circ} \mathrm{C}$ for $15 \mathrm{~min}$ and then incubated at $80^{\circ} \mathrm{C}$ for another $15 \mathrm{~min}$ to partially reverse the nucleic acids' crosslinking. For RNA purification, the samples were DNase-treated and eluted in $30 \mu \mathrm{L}$ of RNase-free water. For DNA purification, the samples were RNase-treated and eluted in a $30 \mu \mathrm{L}$ ATE buffer. The total concentration of both DNA and RNA were spectrophotometrically determined using total absorbance at $260 \mathrm{nM}$, and the purity was quantified using the A260/A280 ratio. RNA samples with A260/A280 ratios of $1.9 \pm 0.2$ were included in this study.

\subsection{Gene Expression Profiling}

The transcriptional profiles were analyzed using the Affymetrix GeneChip ${ }^{\mathrm{TM}}$ Human Gene 2.0 ST Array (Santa Clara, CA, USA), following the manufacturer's instructions. Briefly, $200 \mathrm{ng}$ of total RNA was converted into complementary (c)DNA, labeled with 
the SensationPlus ${ }^{\mathrm{TM}}$ FFPE Amplification and WT Labeling ${ }^{\circledR}$ kit (Affymetrix, Santa Clara, CA, USA) and hybridized on the array, which detects both mRNA and lncRNA. The arrays were washed, stained, and scanned using a GeneChip Scanner 3000 7G (Affymetrix, Santa Clara, CA, USA) [25]. The raw data were background-corrected using Robust Multiarray Average (RMA) [26] and normalized with quantile normalization. Differential expression was determined using linear statistical models with arbitrary coefficients, and one contrast of interest was analyzed using the Bioconductor library limma [27]. Correction for multiple hypotheses was applied using false discovery rate (FDR) [28]. Genes were selected based on an absolute value for the fold-change $|\mathrm{FC}|>2$ and a $p$-value $<0.0002$. The raw and normalized data are available at the gene expression omnibus (GEO) repository with accession number GSE176128. Gene expression data were used to classify the samples according to the TNBC-type algorithm and to analyze for differential expression. A gene set enrichment analysis was performed using MetaCore Clarivate ${ }^{\mathrm{TM}}$ version 2021 (Clarivate Analytics, Paris, Francia).

\subsection{Classification of TNBC Patients in IM and Non-IM Subtypes}

The web-based TNBCtype algorithm (http://cbc.mc.vanderbilt.edu/tnbc/, accessed on 5 June 2021 was used to identify the TNBC mRNA-based subtypes. Based on previously identified centroids, the method establishes six different signatures for subtypes within TNBC: two basal-like (BL1 and BL2), immunomodulatory (IM), mesenchymal (M), mesenchymal stem-like (MSL), and luminal androgen receptor (LAR). All 68 samples were inserted into the algorithm, which classified 55 samples into one of the aforementioned subtypes; in total, 11 samples were labeled as unclassified. This subset of 55 samples was further grouped into the IM subtype $(n=16)$ and the non-IM subtype $(n=39)$ and used for differential expression analysis on coding and non-coding regions of the transcriptome. Within the non-IM group, sample classification included the BL1 \& BL2 $(n=20), \mathrm{M}(n=12)$, MSL $(n=1)$, and LAR $(n=6)$ subtypes (Figure S1).

\subsection{Immunohistochemistry of Tumor Sections}

TNBC is diagnosed based on immunohistochemistry (IHC); the antibodies used were: ER (clone 1D5, Dako, Carpinteria, CA, USA), PR (clone PgR636, Dako, Glostrup, Denmark), HER2 (K5204, Dako, Glostrup, Denmark), and Ki67 (clone Clone MIB-1, Dako, Glostrup, Denmark). Histopathologic analysis of strml and intT lymphocytic infiltration was performed on full-face hematoxylin- and eosin (HE)-stained sections. The intT-TILs are defined as lymphocytes in direct cell-to-cell contact with tumor cells with no intervening stroma, while strml-TILs are scattered or clustered between the carcinoma cells/clusters in the stroma and do not directly interact with tumor cells. Tissue microarrays (TMA) of $5 \mathrm{~mm}$ were cut into $2 \mu \mathrm{m}$ sections with the use of a rotary microtome (RM2125 RTS, Leica Biosystems, Nussloch, Germany) and placed on Matsunami TOMO IHC adhesive glass slides (Ventana, Durham, NC, USA). FFPE sections $(2 \mu \mathrm{m})$ from the TNBC samples were deparaffinized with xylene and rehydrated with a graded ethanol series $(100 \%, 95 \%, 70 \%)$ to distilled water according to standard immunohistochemical protocols. The staining specificity for the IHC was determined using a set of tumor tissues processed in whole sections, with the same fixation and processing methods as the TNBC samples. The optimal concentration of each antibody was established by performing serial titrations on serial FFPE sections. Antigen retrieval conditions and detection methods were also optimized for each antibody to improve sensitivity and signal-to-noise ratio. Briefly, heat-induced antigen retrieval was performed by placing the slides in a Tris-EDTA $(\mathrm{pH} 9)$ or citrate $(\mathrm{pH} 6)$ buffer for $20 \mathrm{~min}$ at $98^{\circ} \mathrm{C}$ using a water bath. The tissue sections were cooled in the buffer for $20 \mathrm{~min}$ before the Peroxidase Blocking Reagent (Dako) treatment for $10 \mathrm{~min}$. The slides were then incubated with Background Sniper (Biocare, Pacheco, CA, USA) for $20 \mathrm{~min}$, and then with anti-CD4 (1:30, clone BC/IF6, Dako, Glostrup, Denmark), anti-CD8 (1:50, clone SP16, Dako, Glostrup, Denmark), anti-FOXP3 (1:100, clone 86D, Biocare, Pacheco, CA, USA), anti-PD-1 (1:200, clone NAT105, Abcam, Cambridge, Cambridgeshire, UK), 
anti-PD-L1 (1:20, clone 28-8, Abcam, Cambridge, Cambridgeshire, UK), and anti-CTLA-4 (1:20, clone F-8, Santa Cruz Biotecnology, Santa Cruz, CA, USA) primary monoclonal antibodies. After washing in PBS, DAKO Envision systems (Dako) or MACH 1 Universal HRP Polymer (BioCare) and diaminobenzidine (DAB; BioCare) were used for chromogenic immunodetection, followed by counterstaining with hematoxylin. Negative control slides without primary antibodies and positive controls for each marker were used for each immunostaining run. Briefly, each section was reviewed at low magnification. Positive lymphocytes in tumor stroma were counted in three high-power fields (HPF; $\times 40$; Olympus BX53, Life Science Solutions, Chicago, IL, USA), representing the staining spectrum seen on the whole section's initial overview and displayed as the average number of stained cells per HPF. A breast cancer expert pathologist, blinded for patient characteristics and outcome, evaluated the TILs and performed the IHC analyses.

\subsection{Next-Generation Sequencing}

Genetic libraries for sequencing were generated for each DNA sample with the commercial capture-based target enrichment panel Solid Tumor Solution STS_v1 (Sophia Genetics, Saint Sulpice, Switzerland). The sequencing was performed using an Illumina MiniSeq instrument (Illumina, Foster City, CA, USA). Multiplexed runs, including 15 libraries each, were carried out using 300 cycle MiniSeq High Output Kits (Illumina, San Diego, CA, USA). The fastq files were analyzed for their quality with FastQC [29] and filtered with trimmomatic [30] before being aligned to the reference genome (GRCh38). The targeted coding exons and splice junctions of known protein-coding RefSeq annotated genes were assessed for an average depth of coverage, with a minimum depth of $30 \times$ required for inclusion in downstream analysis. Local realignment around insertion-deletion sites and regions with poor mapping quality was performed using GATK HaplotypeCaller (Broad Institute, Cambridge, MA, USA) [31], conducting a base quality score recalibration. Variant calls were also identified using GATK HaplotypeCaller. Variants were filtered out based on inheritance patterns, variant type, gene panel, phenotype, and population frequencies. The SOPHiA DDM platform (Sophia Genetics, Lausanne, Switzerland) panel comprehensively assesses target regions in 42 cancer-associated genes (Table S1). The resources included are the HGMD, 1000 Genomes database, RefSeq Genes 109.20201120 v2, NCBI, Transcript Interactions RefSeq Genes 109.20201120 v2, NCBI, gnomAD Exomes Variant Frequencies 2.0.1, Broad Institute of Harvard \& MIT NHLBI GO Exome Sequencing Project, OMIM, PubMed, ClinVar and GenVisR [32].

\subsection{Statistical Analyses}

The summary statistics, including means, medians, ranges, and standard deviations, were calculated on continuous variables; the categorical variables were summarized with proportions and confidence intervals (95\% CIs). Significant differences among continuous variables for non-parametric distributions were assessed using the Mann-Whitney $U$ test. The Chi-square test or Fisher's exact test were used to determine statistically significant differences among categorical variables. The PFS and OS were analyzed using the KaplanMeier method, while the log-rank test evaluated differences among subgroups. Univariate and multivariate analyses of the PFS and OS were performed using the Cox proportional hazard model. Statistical significance was predetermined at a $p$-value $<0.05$ on a two-sided test. The analyses were performed using SPSS version 26 (IBM Company, Armonk, NY, USA) and R statistical software version 4.1.1 (GPL Technologies, Burbank, CA, USA).

\section{Results}

\subsection{Clinicopathological Features of TNBC Patients}

A total of 68 TNBC patients were enrolled in this study, with a median age of 49.5 (30-80) years at diagnosis and an equal proportion of pre- and post-menopausal samples. The most frequent clinical classification at diagnosis was stage III $(83.8 \% ; n=57)$, based on the American Joint Committee on Cancer (AJCC) Staging Manual (8th edition). At least one high-risk 
clinicopathological characteristic was reported for all the clinical stage III patients. High-grade tumors were identified in $88 \%(n=60)$ of the samples. Ductal histology was present in $87 \%$ of patients. Vascular infiltration was observed in $47 \%(n=32)$, and more than half of the cohort $(55.9 \% ; n=38)$ featured a high level (>20\%) of Ki67 (Table 1$)$.

Table 1. Baseline Clinical and Pathological Characteristics of Patients $(n=68)$.

\begin{tabular}{|c|c|}
\hline Variables & $\% n / n$ \\
\hline Age (years) median (min-max) & $49.5(30-80)$ \\
\hline$\geq 40$ & $85.3(58 / 68)$ \\
\hline$<40$ & $14.7(10 / 68)$ \\
\hline \multicolumn{2}{|l|}{ Hormonal Status } \\
\hline Premenopausal & $50(34 / 68)$ \\
\hline Postmenopausal & $50(34 / 68)$ \\
\hline \multicolumn{2}{|l|}{ Clinical Stage } \\
\hline III & $83.8(57 / 68)$ \\
\hline IV & $16.2(11 / 68)$ \\
\hline \multicolumn{2}{|l|}{ Surgical procedure (mastectomy) } \\
\hline Yes & $75.4(43 / 57)$ \\
\hline No & $24.6(14 / 57)$ \\
\hline \multicolumn{2}{|l|}{ Histology } \\
\hline Ductal & $86.8(59 / 68)$ \\
\hline Lobular & $7.4(5 / 68)$ \\
\hline Other & $5.9(4 / 68)$ \\
\hline \multicolumn{2}{|l|}{ Nuclear Grade } \\
\hline G3 & $88.2(60 / 68)$ \\
\hline $\mathrm{G} 2$ & $11.8(8 / 68)$ \\
\hline \multicolumn{2}{|l|}{ Vascular Infiltration } \\
\hline Yes & $47.1(32 / 68)$ \\
\hline No & $52.9(36 / 68)$ \\
\hline \multicolumn{2}{|l|}{ Pathological Complete Response } \\
\hline Yes & $24.6(14 / 57)$ \\
\hline No & $50.9(29 / 57)$ \\
\hline $\mathrm{NE}$ & $24.6(14 / 57)$ \\
\hline \multicolumn{2}{|l|}{ Systemic Treatment } \\
\hline Neo/Adjuvant & $83.8(57 / 68)$ \\
\hline Palliative & $16.2(11 / 68)$ \\
\hline \multicolumn{2}{|l|}{ Radiotherapy } \\
\hline No & $25(17 / 68)$ \\
\hline Yes & $75(51 / 68)$ \\
\hline \multicolumn{2}{|l|}{ Ki67(\%) } \\
\hline$<14$ & $1.5(1 / 68)$ \\
\hline $14-20$ & $2.9(2 / 68)$ \\
\hline$>20$ & $55.9(38 / 68)$ \\
\hline $\mathrm{NE}$ & $39.7(27 / 68)$ \\
\hline \multicolumn{2}{|l|}{$\mathrm{CEA}(\mathrm{ng} / \mathrm{mL})$} \\
\hline$<3.38$ & $79.4(54 / 68)$ \\
\hline$>3.38$ & $19.1(13 / 68)$ \\
\hline $\mathrm{NE}$ & $1.5(1 / 68)$ \\
\hline \multicolumn{2}{|l|}{ CA $15-3(\mathrm{U} / \mathrm{mL})$} \\
\hline$<12.32$ & $20.6(14 / 68)$ \\
\hline$>12.32$ & $77.9(53 / 68)$ \\
\hline $\mathrm{NE}$ & $1.5(1 / 68)$ \\
\hline \multicolumn{2}{|l|}{ Chemotherapy Type } \\
\hline $\mathrm{A}+\mathrm{T}$ & $22.0(15 / 68)$ \\
\hline $\mathrm{A}+\mathrm{T}+\mathrm{Cis}$ & $61.8(42 / 68)$ \\
\hline A or $\mathrm{T}$ & $16.2(11 / 68)$ \\
\hline
\end{tabular}




\subsection{Treatment Management of TNBC Patients}

All the patients with locally advanced disease $(83.8 \% ; n=57)$ received neoadjuvant chemotherapy; of these, only $14(24.6 \%)$ underwent a pCR, and $43(75.4 \%)$ underwent a radical modified mastectomy. The preferred neoadjuvant treatment was an anthracycline and taxane-based chemotherapy regimen; notably, 42 (61.8\%) patients received platinum as a third agent. For patients with clinical stage IV, anthracycline- or taxane-based chemotherapy was administered. Remarkably, immunotherapy was not administered, neither in the locally advanced nor in the metastatic setting, mainly due to access barriers.

Out of the cohort of 57 patients with clinical stage III disease, $70.2 \%$ did not respond to treatment. Forty patients had at least one high-risk pathological feature (positive axillary lymph nodes, histologic grade 3, Ki-67 index $>20 \%$ or lymphovascular invasion), among which the patterns of recurrence were the following: $25(43.9 \%)$ had central nervous system (CNS) involvement, 21 (36.8\%) lung metastases, 12 (21.1\%) bone metastases, and $11(19.3 \%)$ developed liver metastases (Table S2).

\subsection{Classification of TNBC Patients into IM and Non-IM Subtypes}

According to the Lehmann subtypes, out of the 68 tumor samples, 55 were classified as IM and non-IM (Table 2). The IM subtype was the most common in our TNBC cohort, being found in 16/68 (23.5\%) of the cancers examined, followed by the BL1 and BL2 subtypes found in $20 \%$ of cases. Figure S1 shows the complete analysis per sample based on Lehmann subtypes. The Strobe flow diagram in the Supplementary Materials describes further details regarding the complete analysis of tumor samples (Figure S2).

Table 2. Molecular Subtype by Lehmann et al. [4].

\begin{tabular}{ccc}
\hline IM and Non-IM & Subtype & $\%(n / n)$ \\
\hline IM & IM & $23.5(16 / 68)$ \\
& BL1 & $14.7(10 / 68)$ \\
Non-IM & BL2 & $14.7(10 / 68)$ \\
$57.3(39 / 68)$ & LAR & $8.8(6 / 68)$ \\
& M & $17.6(12 / 68)$ \\
& MSL & $1.5(1 / 68)$ \\
& UNS & $19.1(13 / 68)$ \\
\hline
\end{tabular}

IM: Immunomodulatory; BL1: basal like 1; BL2: basal like 2, M: mesenchymal; MSL: mesenchymal stem-like LAR: luminal androgen receptor; UNS: unclassified.

\subsection{TILs Subpopulations in the IM Subtype}

Thirty-nine specimens were available for the TILs subpopulation analysis: IM subtype $(n=13)$ and non-IM subtypes $(n=26)$. The analysis showed a higher but non-significant intT infiltration of CD8+ (Th1) TILs in the IM subtype when compared with the non-IM subtype (20\% (95\% CI: 9.4-38.6) vs. $10 \%(7.16-15.45) ; p=0.058)$ (Figure 1). Moreover, no significant differences were identified between the two subtypes in terms of CD8+ strml TILs. For CD4+ TILs (Th2), we did not identify any associations regarding the intT nor strml infiltration and the tumor subtypes.

Lastly, the IHC analyses showed that the most predominant TILs phenotypes in the TNBC samples were Treg cells (FOXP3+). Interestingly, most cells featured positive cytoplasmic staining vs. nuclear for this particular marker. A significant difference was observed when comparing the proportion of FOXP3+ intT cells in IM vs. non-IM subtype tumors $(15 \%$ vs. $5 \% ; 95 \% \mathrm{CI}, 8.49-23.21 ; p=0.004)$. In the case of strml this difference was also statistically significant between the IM and non-IM subtypes ( $40 \%$ vs. $14 \%$; $95 \%$ CI, 26.80-58.27; $p=0.001$ ) (Figure 1). 
(a)

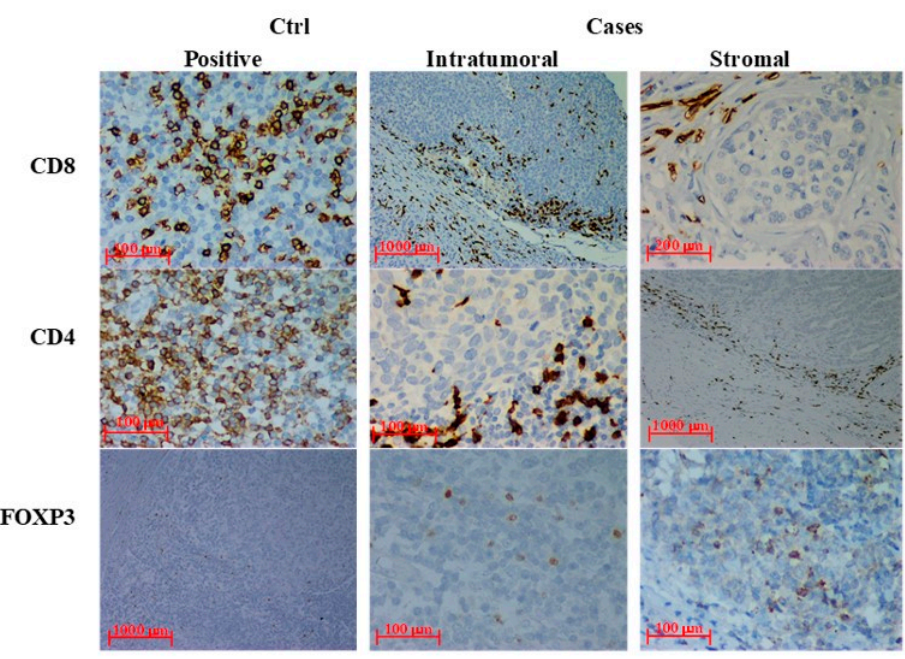

(b)
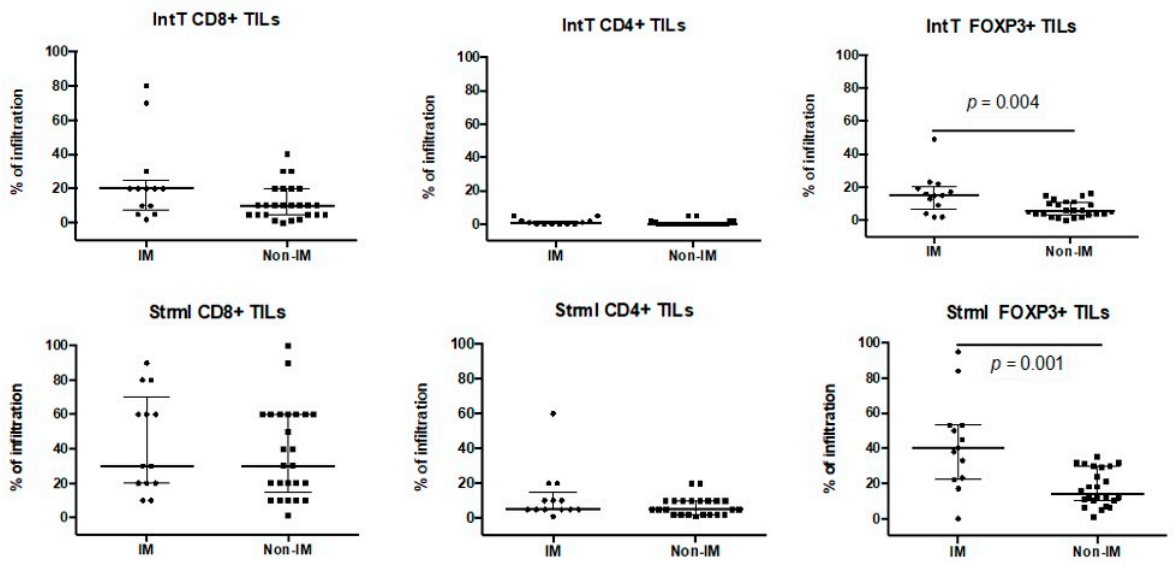

Figure 1. Tumor infiltration lymphocytes (TILs) in the immunomodulatory (IM) subtype vs. nonIM subtype. (a) Representative images of immunohistochemistry depicting both intratumoral (intT) and stromal (strml) infiltrating lymphocyte subpopulations $(\mathrm{CD} 4+(\mathrm{ctrl} \times 40$, int $\mathrm{T} \times 40$, strml $\times 4)$; CD8+ $(\operatorname{ctrl} \times 40$, intT $\times 4$, strml $\times 20)$, and FOXP3+ $(\operatorname{ctrl} \times 4, \operatorname{intT} \times 40$, strml $\times 40))$ in TNBC biopsies. (b) Scatter plots (percentages) compare median and data distribution between IM vs. nonIM subtypes, both int T and strml per lymphocytes subpopulation (with interquartile range bars and the median); differences assessed using the Mann-Whitney $U$ test; statistically significant differences are shown in each plot. Ctrl: controls.

\subsection{Differential Expression of Coding and Long Non-Coding RNAs}

We conducted a differential gene expression analysis on both coding and long noncoding regions in order to characterize differences among samples classified as IM and non-IM subtypes. The results from this analysis showed a total of 74 genes with differential expression (DEGs) when comparing IM vs. non-IM samples. In all cases, differential expression resulted in a significant up-regulation of these genes in the IM subtype, with $\mid \mathrm{FCl}>2$ and a $p$-value $<0.0002$ (Table S3). We further performed unsupervised hierarchical clustering (Figure 2a), which identified several patterns in terms of DEGs. This is illustrated in the heatmap shown in Figure 2a, in which the IM samples (shown in magenta) clustered to show a pattern indicating gene overexpression, compared with non-IM samples (shown in teal). To explore gene function, a gene set enrichment analysis of the genes expressed in the IM group identified biological processes associated with the immune system relevant to our working hypothesis. Pathway analysis revealed enrichment of the $\beta$-catenin signaling pathway (known to be highly relevant in human cancers) (Figure 2b) in $16 \%$ of the genes we identified as differentially expressed. 


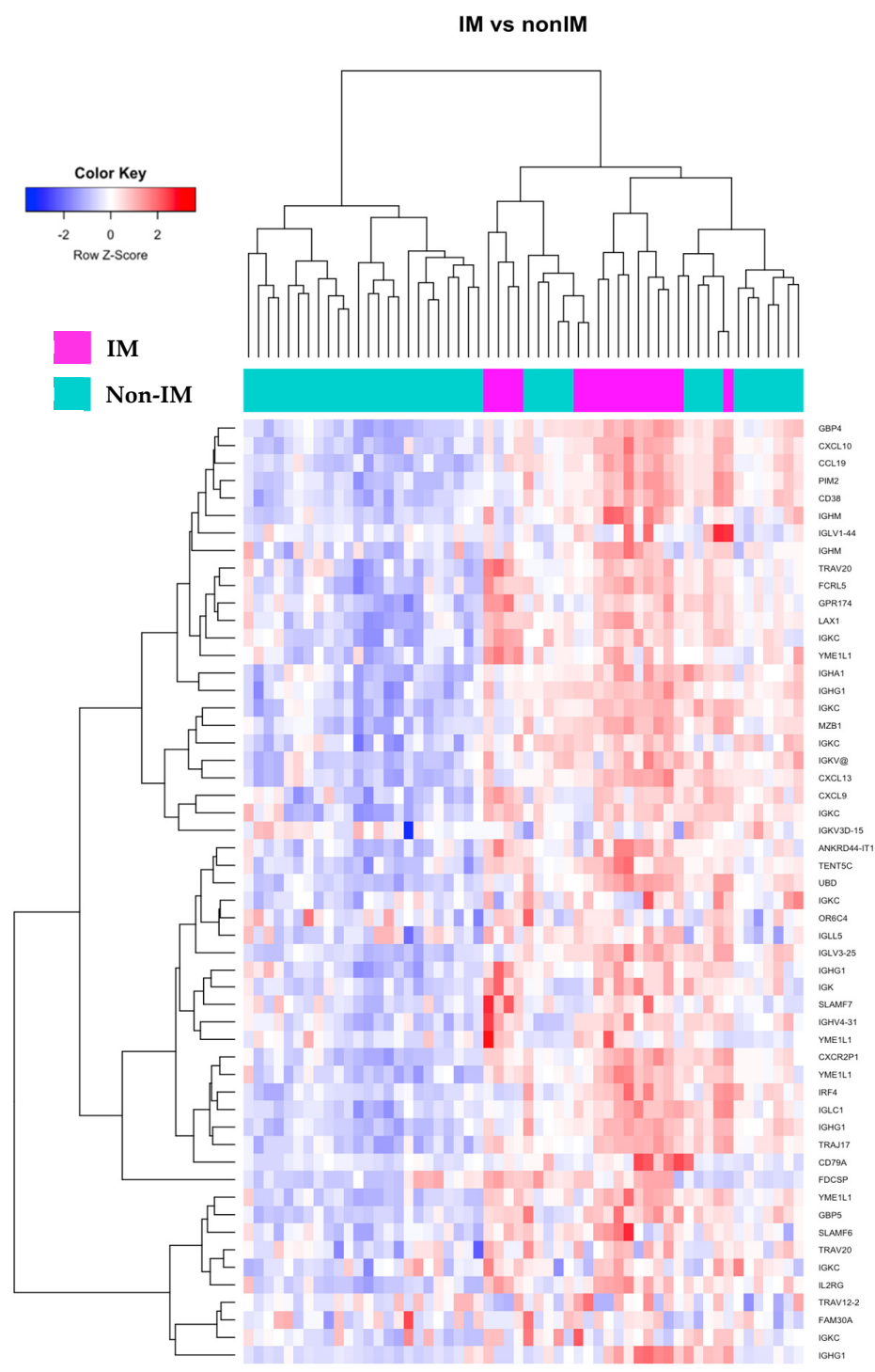

(a)
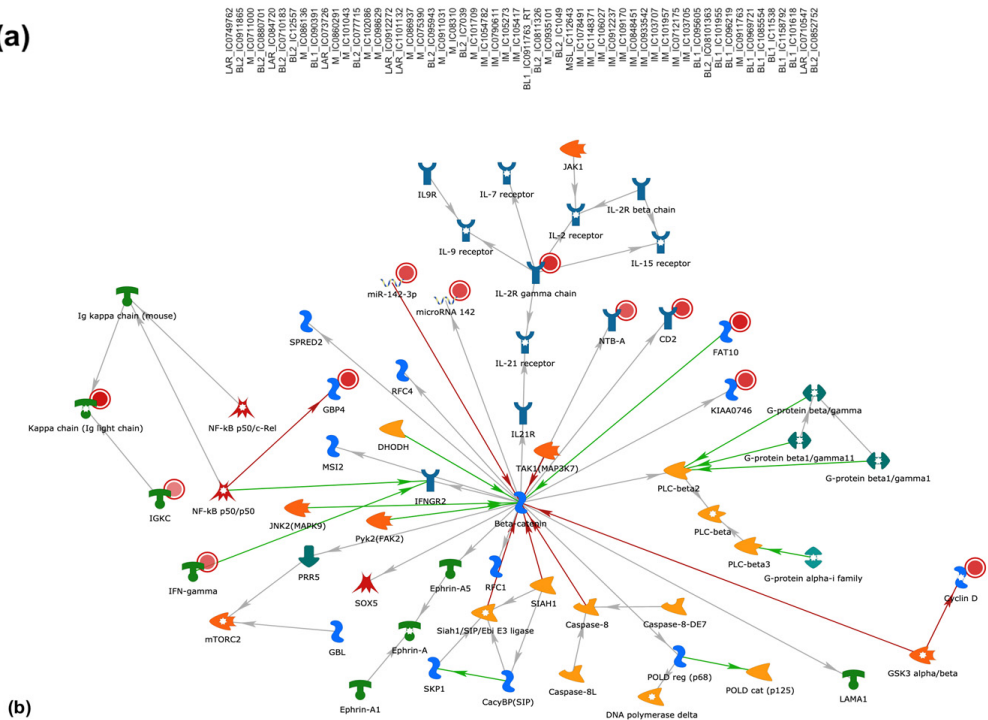

Figure 2. Gene expression analysis (a) heat map resulting from an unsupervised hierarchical clustering, the top bar of the heat map shows in magenta the IM samples and in light green the non-IM. Red indicates gene overexpression; columns are samples and rows are genes. (b) Enrichment analysis using Metacore Clarivate $^{\mathrm{TM}}$ highlighted the $\beta$-catenin signaling pathway; red dots mark the genes in our list. 


\subsection{LncRNAs Associated with the IM Subtype}

The differential expression analysis of the long non-coding regions of the transcriptome between the IM and non-IM samples was sparser compared with the coding sequences. From this analysis we identified seven long non-coding RNAs differentially expressed (six up-regulated $(\uparrow)$ and one down-regulated $(\downarrow))$ based on $|\mathrm{FC}|>2$ and

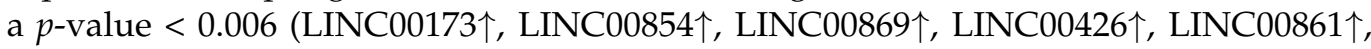

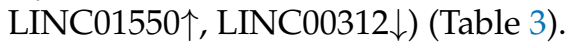

Table 3. Summary statistics from a linear model to determine long non-coding RNAs differential expression in IM vs. non-IM samples.

\begin{tabular}{cccccc}
\hline lncRNA & FCH & Mean Expression & $\boldsymbol{t}$-Test & $\boldsymbol{p}$ Value & adj. $\boldsymbol{p}$ Value \\
\hline LINC00861 & 1.64 & 4.800199 & 4.982293 & $5.82 \times 10^{-6}$ & 0.00182405 \\
LINC00869 & 1.49 & 6.408327 & 3.61491 & $6.23 \times 10^{-4}$ & 0.083770344 \\
LINC00426 & 1.38 & 4.920571 & 5.373881 & $1.38 \times 10^{-6}$ & 0.000647671 \\
LINC01550 & 1.35 & 4.084667 & 5.5031 & $8.50 \times 10^{-7}$ & 0.000647671 \\
LINC00854 & 1.32 & 6.853894 & 3.699587 & $4.76 \times 10^{-4}$ & 0.074699771 \\
LINC00312 & -1.29 & 3.827583 & -2.835162 & $6.26 \times 10^{-3}$ & 0.317551682 \\
LINC00173 & 1.26 & 4.548792 & 3.099832 & $2.97 \times 10^{-3}$ & 0.199410413 \\
\hline
\end{tabular}

LINC: long intergenic non-coding; FCH: fold-change; adj. adjusted.

Figure 3a shows the results from the unsupervised hierarchical clustering approach, highlighting the patterns of expression clustered by subtype. The figure shows an opposite expression pattern among the mesenchymal subtype and the IM subtype samples.

PCA with all IncRNAs

(a)
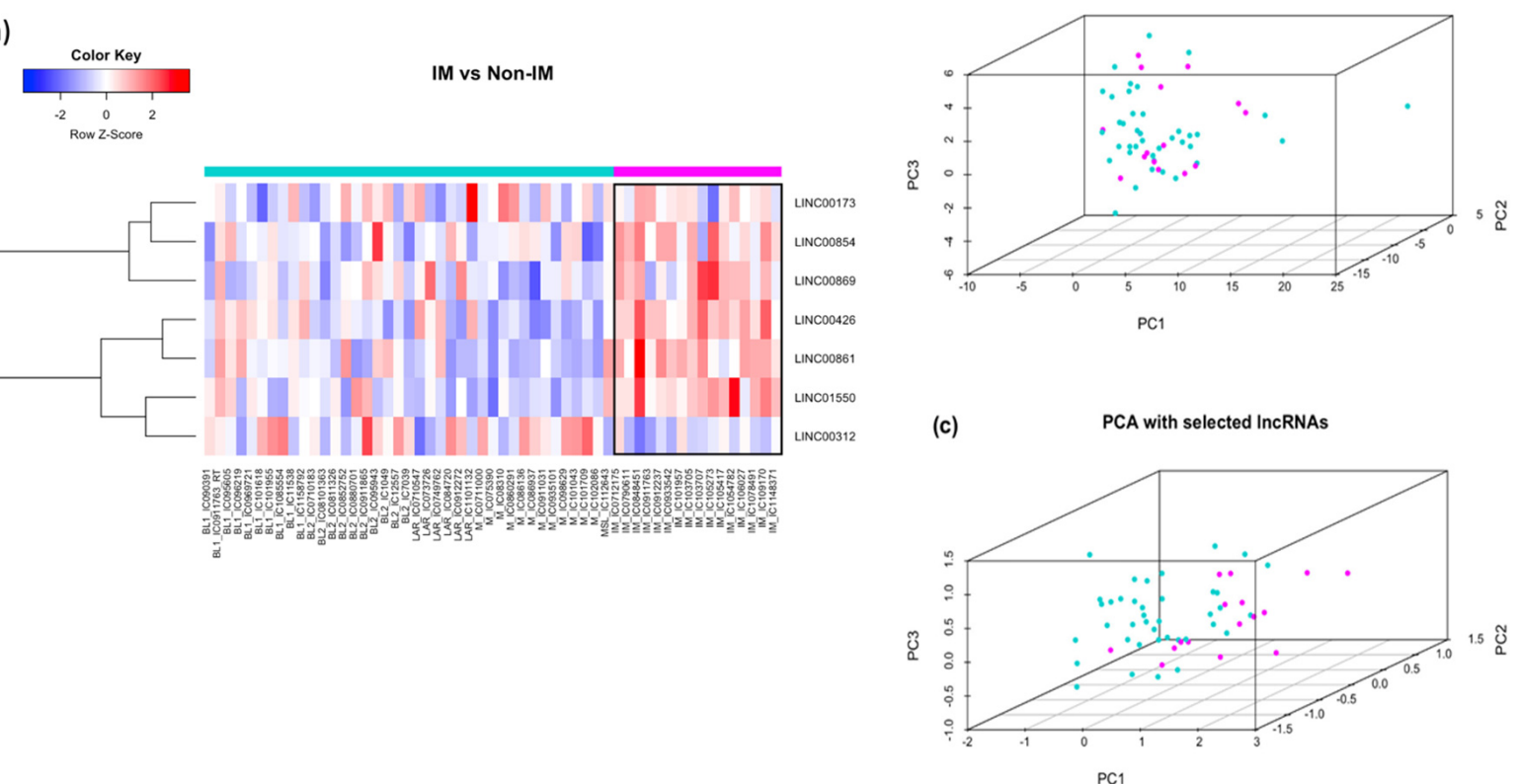

Figure 3. Differential expression of lncRNA between IM vs. non-IM subtypes. (a) Heat map from an unsupervised hierarchical clustering of selected lncRNAs based on fold-change $\geq 1.2$ and significance level $p$-value $<0.006$. The top bar in magenta shows samples classified as IM; the teal bar represents those classified as non-IM. Red represents up-regulation and blue down-regulation. (b) Principal component analysis (PCA) showing a 3D plot of IM (magenta) vs. non-IM (teal) samples when all annotated lncRNAs are used. (c) The same plot when using only the seven most significant lncRNAs, which better classifies the IM and non-IM subtypes under analysis. PC: principal components; lncRNA: long non-coding RNA, IM: immunomodulatory.

A principal component analysis (PCA) was performed to evaluate the effect of those seven long intergenic non-coding RNAs separating the IM from the rest of the subtypes. Figure $3 b$ displays the PCA using all annotated lncRNAs in the microarray where the first 
three principal components can only accumulate $31.7 \%$ of the total variability in the data for all the samples. By contrast, Figure 3c shows the PCA using only the seven statistically significant lncRNAs; in this case, the first three principal components account for $77.43 \%$ of the total variability. Though the classification is not perfect, we were able to identify those that best separate the two groups. Summary statistics after fitting the linear model are presented in Table 3. All seven IncRNAs were statistically significant according to the $p$-value, but only five remained significant after FDR adjustment for multiple hypotheses represented in the adjusted $p$-value.

\subsection{PD-1, PD-L1, and CTL-4 Expression in the IM Subtype}

Even though PD-1+ TILs were identified in $97.4 \%$ of the tumor samples in the IM subtype group, PD-1+ expression in tumor cells did not differ significantly between each subtype. In the other assessments, we identified a clear increase in expression for the IM subtype compared with the non-IM (Figure 4a). In the case of PD-1+ TILs, we observed an increase in the IM subtype for both intT 10\%(IM) vs. $2 \%$ (non-IM) $(p=0.051)$, and strml $20 \%(\mathrm{IM})$ vs. $10 \%$ (non-IM) $(p=0.095)$, although this difference did not reach statistical significance (Figure $4 \mathrm{~b}$ ). However, PD-L1 + expression in tumor cells was significantly higher $(p=0.004)$; CTLA-4+ TILs were also significantly higher in int $\mathrm{T}(p<0.001)$ and strml $(p=0.006)$ assessments, respectively.

(a)
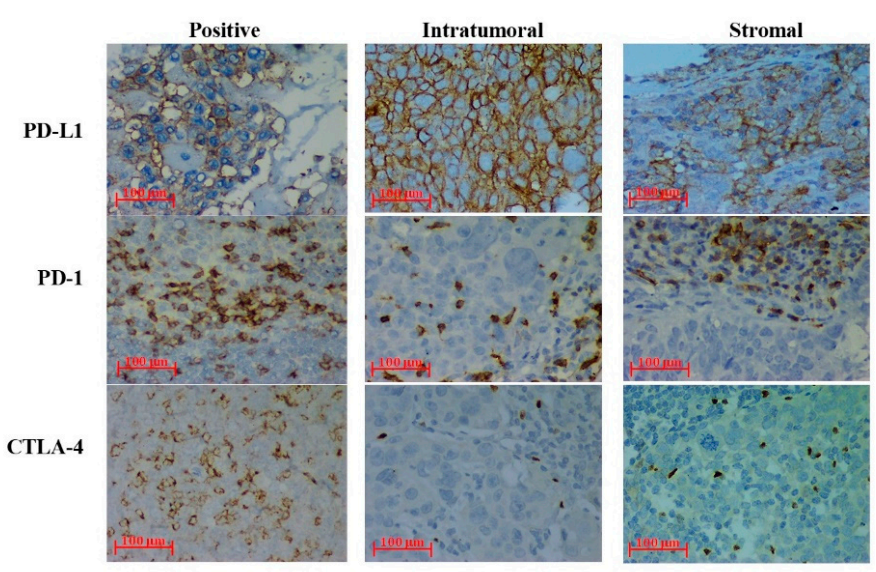

(b)
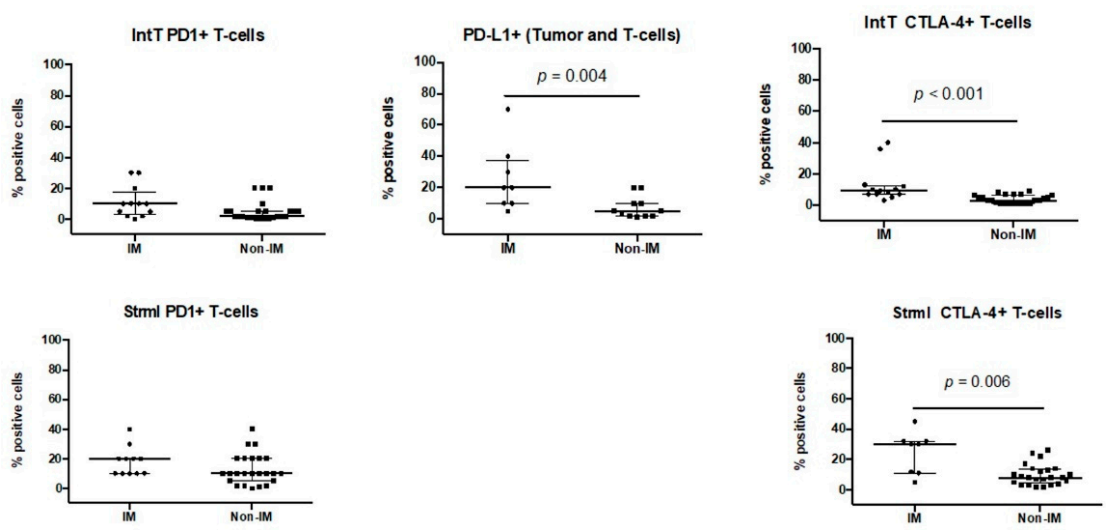

Figure 4. Expression of immune checkpoints in IM vs. non-IM subtypes. (a) Immunohistochemistry images of both intratumoral (intT) and stromal (strml) immune checkpoints (ICp) [PD-L1+ (ctrl $\times 40$, intT $\times 40$, strml $\times 40)$; PD- $+(\operatorname{ctrl} \times 40$, intT $\times 40$, strml $\times 40)$, and CTLA-4+ $(\operatorname{ctrl} \times 40$, intT $\times 40$, strml $\times 40$ )] in TNBC biopsies. (b) Scatter plots (percentages) comparing median and data distribution between IM vs. non-IM subtypes, both intT and strml per ICp positive cells (with interquartile range bars and the median); differences assessed using the Mann-Whitney $U$ test; statistically significant differences are shown in each plot. Ctrl: controls. 


\subsection{Comparison of Mutation Frequency between IM and Non-IM Subtypes}

We identified genetic alterations in 42 clinically relevant genes associated with solid tumors in 29 TNBC samples (11 IM and 18 non-IM) (Figure 5). A total of 3216 somatically acquired base substitutions were identified; among these, 2294 were in intronic sites. There were 162 missense, 13 nonsense, 3 essential splice-site, and 281 silent mutations in the protein-coding regions. A total of 176 intergenic region mutations were observed in $40 \%$ of genes included in this 42 gene panel. Out of the nine indels identified, five were frame-shift deletions, four in TP53 and one in SMAD4; two in-frame deletions were identified, one in TP53 and the other in KIT; additionally, two insertions, both in TP53, were observed. The summary of the mutations is shown in Figure 5.

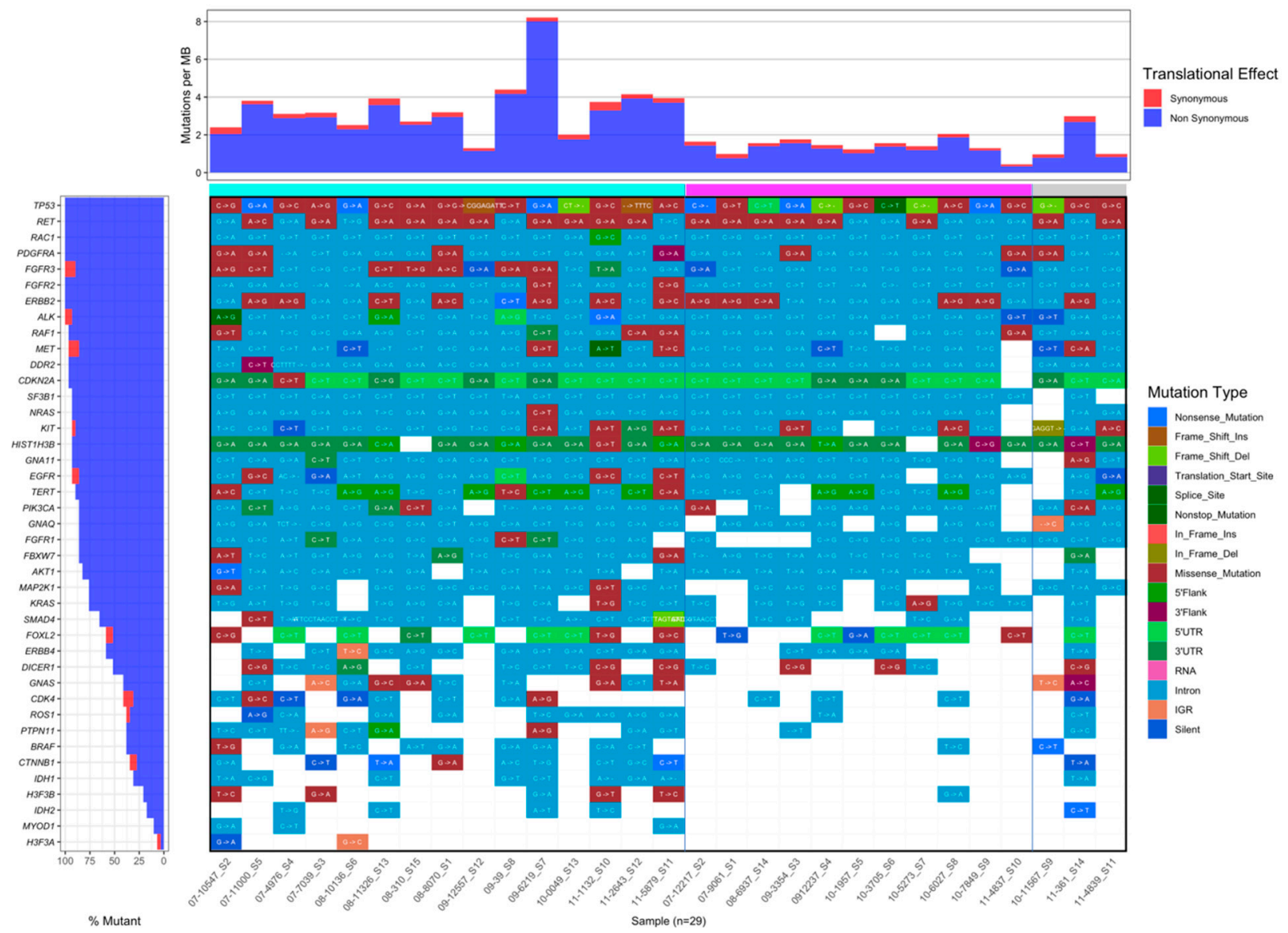

Figure 5. Comparison of pathogenic mutation by type and frequency in IM subtype (magenta) and non-IM subtypes (teal) according to the Lehmann classification for TNBC patients. The last three samples (light gray) are unclassified samples, which were sequenced for comparison reasons. The top bar shows the mutation rate by translational effect per sample, and the left bar plot shows the mutation rate and its translational effect by gene; synonymous variants are marked in red and non-synonymous in blue. The top mutated gene is TP53, followed by RET, RAC1, and PDGFRA.

We further observed a difference in terms of the mutation rate between the IM (top bar in magenta) and non-IM (top bar in teal) subtypes. Within the latter, there were three samples that could not be classified using Lehmann's algorithm (far-right columns with the top bar in light grey). The blue/red bars on top of the main plot show the mutation rate per sample, represented as synonymous (red) and non-synonymous (blue) alterations. Notably, the non-IM subgroup is characterized by a higher number of mutations, and a higher abundance of missense variants. At the bottom of the left bar plot, low-mutated genes can be observed, featuring a sparse mutation pattern for the IM samples. We found five mutation-free genes (GNAS, CTNNB1, IDH1, IDH2, MYOD1) and two that might be potential biomarkers for TNBC immunotherapy; CTNNB1 (Catenin beta-1) and IDH1. For 
IDH, no mutations were found for the IM samples and $50 \%$ of the non-IM samples featured a mutated version of this gene. For the case of $I D H 2$, no mutations were found in the samples from the IM group and $28 \%$ in the non-IM samples; all but one was intronic, and the other was a non-sense mutation.

\subsection{Clinical Variables and Outcomes}

The clinical and pathological variables associated with the IM subtype included vascular invasion and low probability of metastasis to the lung, liver, and central nervous system (Table S4). The Kaplan-Meier curves for recurrence-free survival (RFS) in stage III patients and for overall survival are shown in Figure 6. A total of 51 (75\%) patients died due to disease progression during follow-up. In both plots, we observe how different the survival rate is for IM subtype patients compared to each of the other subtypes. This result suggests that the IM subtype featured the more favorable prognosis of all molecular subtypes.
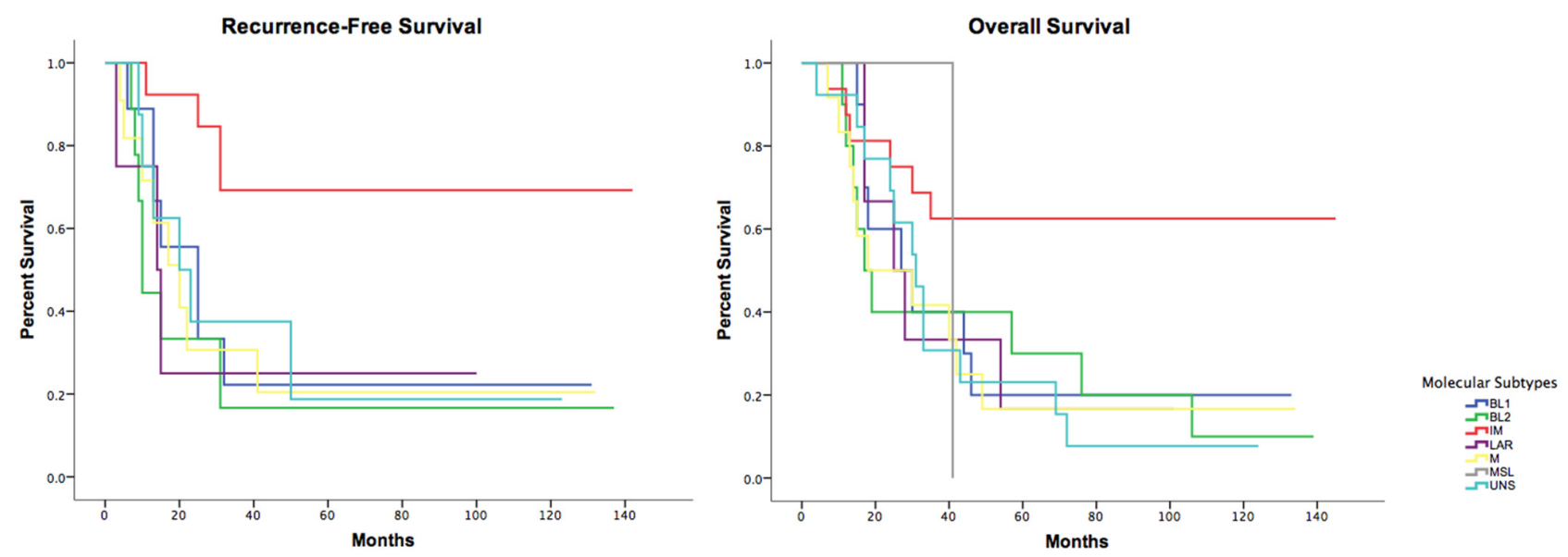

\begin{tabular}{cccccc}
\hline Subtype & Median (months) & $\mathbf{( 9 5 \% ~ C I ) ~}$ & Subtype & Median (months) & $\mathbf{( 9 5 \% ~ C I ) ~}$ \\
\hline BL1 & 25 & $(11.1-38.9)$ & BL1 & 27 & $(8.4-45.6)$ \\
BL2 & 10 & $(8.5-11.5)$ & BL2 & 17 & $(10.8-23.2)$ \\
IM & NR & NR & IM & NR & NR \\
LAR & 14 & $(2.2-25.7)$ & LAR & 25 & $(11.8-38.2)$ \\
MSL & - & - & MSL & 41 & NS \\
M & 20 & $(9.5-30.5)$ & M & 31 & $(24-38)$ \\
UNS & 20 & $(6.1-33.9)$ & UNS & 30 & $(22.9-37.1)$ \\
\multicolumn{2}{l}{ Log-Rank Test, $p=0.049^{*}$} & & Log-Rank Test, $p=0.139$ \\
\hline
\end{tabular}

Figure 6. Kaplan-Meier curves for recurrence-free survival in patients with stage III disease (left) and overall survival (right) for all samples classified with different molecular TNBC subtypes. ${ }^{*} p<0.05$. CI: confidence interval; BL1 basal like 1; BL2: basal like 2; IM: immunomodulatory; MSL: mesenchymal stem-like; M: mesenchymal; NR: not reached; NS: non-significant.

In the multivariate analysis, the type of breast surgery and previous CNS radiotherapy increased the risk of death and recurrence significantly. Interestingly, after adjusting for significant factors in the univariate analysis, the IM subtype positively influenced RFS and OS in patients with TNBC, representing a protective factor. The complete model is shown in Table S5.

\section{Discussion}

Currently, immunotherapy benefits seem to be confined to TNBC PDL-1 positive patients in advanced stages or earlier stages as a neoadjuvant strategy $[16,19,33]$. Remarkably, contradictory data [34] have undermined currently approved immunotherapy indications [35], emphasizing the necessity of continuing to explore and characterize the TNBC subtype. Even though some immune subclassifications have been developed, to date, none has been incorporated systematically into daily clinical practice. Nonetheless, 
individualized therapies have been suggested according to each TNBC subtype, based on molecular and immune data [36].

The present study presents relevant information derived from a cohort of 68 TNBC patients classified by the Lehmann algorithm $(n=55)$, who were grouped according to immunomodulation into IM $(n=16)$ and non-IM $(n=39)$ subtypes. Lehmann et al. excluded the IM and MSL subtype in the more recent TNBC classification, arguing that the transcripts in the original classification came from lymphocyte infiltration and tumorassociated stromal cells infiltration of immune cells rather than the tumor cells. The recent advent of immunotherapy in different clinical scenarios of the TNBC and the evidence from translational medicine studies have supported the necessity of visualizing this disease from a global point of view and pursuing the characterization of the immune milieu and the whole tumor microenvironment instead of a reductionist approach limited to characterizing just the tumor. [37-39]. We present a multi-omics analysis complemented with clinical data contrasting the behavior of IM vs. non-IM disease subtypes, exploring protein-coding genes, long intergenic non-coding RNAs, TILs, DNA mutation rates, clinical, histopathological, and survival patterns.

Gene expression analysis on coding genes identified a list of 74 DEGs, all up-regulated in IM when contrasted with the non-IM samples. The gene set enrichment analysis revealed that the $\beta$-catenin pathway is associated with $16 \%$ of the genes differentially regulated in the IM subtype in our study. It has been reported that the Wnt $/ \beta$-catenin signaling is associated with cancer; this signaling disrupts the tumor-immunity in most nodes, including $T$ cells and tumor cells cycle, facilitating cancer development and preventing spontaneous T-cells infiltration across most human cancers [40,41]. Both the canonical and non-canonical Wnt/ $\beta$-catenin pathways are essential for mammary gland development [42] and BC growth and dissemination [43]. In fact, breast cancer patients with activation of the WNT/ $\beta$-catenin pathway have been associated with earlier stages of the basal-like subtypes, suggesting that the activation of this pathway might be an early event in breast cancer genesis [44]. A recent study showed that the $\beta$-catenin inhibitor enhanced T-cell infiltration, shifting the tumor microenvironment into a T-cell-inflamed phenotype. Furthermore, it has been reported that $\beta$-catenin status could potentially serve as a clinical predictor of immunotherapy outcome [45]. Therefore, we propose that the Wnt/ $\beta$-catenin pathway might be evaluated in future studies exploring the treatment effect in combination with immunotherapy [46].

On the other hand, accumulating evidence indicates that lncRNAs are encouraging biomarkers involved in regulating gene expression and cancer biology [47]. One example is lncKLHDC7B, which was involved as a transcriptional modulator of proapoptotic signals and avoided cell migration and invasiveness [48]. According to Lehmann's classification, we explored these non-protein-coding molecules through a differential expression analysis between the IM subtype and non-IM subtypes. The analysis identified seven lincRNAs associated with the TNBC-IM subtype; this subtype showed a better prognosis compared to non-IM subtypes. Our study demonstrated an opposite expression pattern of lncRNA expression between the IM subtype and mesenchymal type, both reported in immune regulation. In this regard, MSL cells promote inflammation when the immune system is not fully activated or limit inflammation if the immune system is overwhelmed as it fights cancer [49]. Of those seven lincRNAs, LINC01550 and LINC00426 were identified as oncogenesis regulators in non-BC tumors [50,51] and only three (LINC00173, LINC00861, LINC00312) were identified in BC [52-54]. However, we found evidence of association in four regarding tumor immune regulation: LINC00426, LINC00173, LINC00861, and LINC00312. LINC00426 has been associated with an increase in CD8+ TILs and macrophage M2 infiltration [55]. Two more, LINC00173 [56] and LINC00861, regulate immune signaling pathways and immune checkpoints, specifically PD-1 and CTLA-4 [57]; and as we discuss next, CTLA-4 was found with high expression in the IM subtype. LINC00312 overexpression has been reported as an inducer of aggressiveness in tumors [58] and was found to be downregulated in the IM subtype in our study, from which we could associate 
this downregulation to a good prognosis. Moreover, LINC00312 is associated with the Wnt- $\beta$-catenin pathway [59], which was enriched in the IM subtype from the coding genes analysis, and LINC00173 has also been reported as a regulator of $\beta$-catenin expression [60]. Furthermore, LINC00861 [61] and LINC00312 [62] are associated with the PI3K/AKT pathway, which is, in turn, associated with immune response [21]. We also found two new lincRNAs upregulated in the TNBC-IM subtype LINC00854 and LINC00869, with little to no association with disease or molecular function. However, altogether, this suggests an involvement in the tumor immune response, and thereby, further studies are required to clarify their signaling pathway involvement.

Mutation rates between the IM and the non-IM subtypes also showed substantial differences. We highlighted two genes because of their relevance to immune system response and because no mutations were found in the IM samples. We presented CTNNB1 (Catenin $\beta-1$ ), a key downstream component of the canonical Wnt signaling pathway [63-70]; it was also found relevant to explain results from the transcriptomic analysis and to discuss the tumor immune-microenvironment regulation. Other pathways are those related to IDH1, the abnormal conversion of 2-oxoglutarate to 2-hydroxyglutarate, and the innate immune system. Although this type of mutation can either make a protein more effective or defective, in this case, it could be the latter; it was notable that the non-IM subtypes demonstrated a worse prognosis than the IM subtype considering only genes relevant in cancer. Further studies are needed to clarify the participation of these genes in the immune milieu.

With the primary aim to ameliorate immunotherapy advances for TNBC, TILs have been associated with better prognosis and predictive value $[8,9,12]$. However, it is still unclear which immune cell types contribute the most to outcome improvement. This study analyzed TIL subpopulations in the IM subtype of our cohort. The results showed higher FOXP3-TILs (Treg) infiltration in both intT and strml within this subtype. We also observed a trend toward high CD8-TILs (Th1) infiltration. Tumor infiltration, predominantly by Tregs, was associated previously with unfavorable histologic features and poor survival outcomes in breast cancer [71], mainly through transforming growth factor (TGF- $\beta$ ) and IL-2 stimuli promoting an immunosuppressive microenvironment [72].

By contrast, other studies have postulated that an increased number of int Tregs has been associated with better clinical outcomes, reinforcing the idea that the type of immune cell and interaction is essential, as well as the density and specific location [73]. In line with this, we also found that Tregs may be a favorable prognostic factor for recurrence-free and overall survival in the IM subtype in an independent way to current biomarkers. This has been confirmed mainly when intT Tregs are accompanied by CD8-TILs and CD20+ B cells [74]. Furthermore, Tregs work in conjunction with Th17 cells through TGF- $\beta$, thereby prompting differentiation of the Th17 phenotype from CD4+ Th2 cells (in the presence of IL-6) and Tregs [75]. Th17 cells can acquire Th1-like characteristics due to their plasticity (ex-Th17 cells or non-classical Th1 cells) after activation, enhancing the antitumor immunity through pro-inflammatory signals [76]. Therefore, we suggest the key participation of Th17 response in the IM subtype due to low infiltrations of classical Th1 response.

We also report that the IM subtype was characterized by a high CTLA-4 expression of intT and strml T-cells in the IHC analysis, associated with a high PDL-1 positivity in the tumor and increased PD1+ TILs density. Although the clinical significance of ICp is still under debate, PD-L1 expression has been independently associated with a worse prognosis [77]. Similarly, Ren et al. stated that PD-1 was linked with PDL-1 expression and increased density of TILs, which may positively impact and modify prognosis [77]. In the present study, the IM subtype exhibited a longer OS and a more prolonged RFS considering just high-risk stage III patients. However, the lack of standardization in the staining procedures of ICps in TNBC may result in inconsistent results and performance in clinical studies.

PD-L1 positivity has been reported from 19\% to 64\% [78]; herein, the IM tumor samples showed 20\% PD-L1 positivity, 30\% int T CTLA-4, and 9\% strml CTLA-4 expression, which are in agreement with previous reports. Leisha et al. reported a sub-analysis of 
IMPASSION 130 following three distinct immune subtypes: inflamed, immune exclude, and desert; the inflamed subtype presented the highest PD-L1 expression. Another key finding was its benefit from immunotherapy (HR 0.63, 95\% CI 0.49-0.81) [42], which is encouraging and influenced this study [79].

Adverse and immune-related adverse events associated with immunotherapy administration are more prevalent with CTLA-4 inhibitors [80]. Th17 cells and IL-17 might play an essential role in the efficacy and toxicity of ICIs, wherein toxicities have correlated with antitumor response [81]. The immunoregulatory role of Th17 and its influence on toxicity could be evaluated in the future to increase tolerability and adherence to treatment. Considering the high positivity of CTLA-4 staining in the IM subtype and the potential benefit of this immune pathway may be promising to assess its efficacy with an optimal treatment administration.

Our study features some limitations. We recognize that the small sample size and retrospective nature did not include patients treated with immunotherapy. However, the hypotheses did not include before and after immunotherapy but, rather, molecular and clinical differences that support the TNBC subtype classification by Lehmann. The sample size also precludes the performance of a subset analysis of TILs and their association level, as well as immune signature scores with clinical characteristics, which were carefully conducted. TMA may incorporate some bias; however, we worked around this by sampling three representative regions from every tumor.

\section{Conclusions}

TNBC is a highly aggressive breast cancer subtype. This study presents evidence regarding the IM subtype within TNBC. Our results show that it features an increased FOXP3+ TILs infiltration and a high CTLA-4 and PD-L1 immune checkpoints expression. We also identified long intergenic non-coding RNAs associated with immune responses. The transcriptomic and enrichment analyses identified the $\beta$-catenin signaling pathway characterizing the IM subtype from other breast tumor microenvironments. The DNA sequencing analysis revealed differences in both mutation rates and mutation type. Overall, we were able to identify novel lincRNA biomarkers from a thorough characterization of the molecular and immune milieu of the IM subtype, highlighting the importance of algorithms for patient classification but also for the design of future clinical trials in which an immune-based therapy could benefit this subgroup of patients.

Supplementary Materials: The following are available online at https:/ / www.mdpi.com/article/10 .3390 / cancers13246256/s1, Figure S1: Distributions of the Vanderbilt subtypes in Mexican women with triple-negative breast cancer (TNBC) $(n=68)$ : basal-like 1 (BL1), basal-like 2 (BL2), immunomodulatory (IM), luminal androgen receptor (LAR), mesenchymal (M), and mesenchymal stem-like (MSL), Figure S2: Strobe flow diagram, Table S1: Gene content of cancer panel, Table S2: Type of Recurrence Sites of Stage III Patients $(n=57)$, Table S3: Differential gene expression analysis coding and long non-coding regions; Table S4: Clinical and pathological characteristics of TNBC patients with IM and non-IM subtypes, Table S5: Univariate and multivariate analysis with RFS and OS of TNBC patients.

Author Contributions: R.R.-B. performed most of the experimental work and some data analysis. A.O.-G., P.C.-G. and C.V.-G. oversaw the project from sample collection to RNA extraction and microarray processing. O.A. and C.R.-E., both of whom are corresponding authors, led the clinical and omics research and work. O.A., C.R.-E. and R.R.-B. are the guarantors of the manuscript's content; P.C.-G. and C.V.-G. oversaw the clinical follow-up of the patients and made substantial contributions to the conception and design of the study. C.H.C.-S. performed the histopathological review of all the cases. E.G.-M., S.Á.-R., M.M.-F., G.R.-T. contributed with sequencing data. R.R.-B., G.J.A.-F. and C.R.-E. analyzed and presented all the data included in this study. The formal analysis was conducted by R.R.-B., G.J.A.-F., E.G.-M., J.D.-C., C.V.-G. and C.R.-E.; the investigation by R.R.-B., C.H.C.-S., P.C.-G., C.V.-G. and N.Y.H.-P., R.R.-B., P.C.-G., C.R.-E., L.L.-M. and N.Y.H.-P. prepared the manuscript; the data curation was performed by, R.R.-B., G.J.A.-F., E.G.-M., S.Á.-R., M.M.-F., A.O.-G. and L.L.-M.; the methodology was designed by R.R.-B., P.C.-G., E.G.-M., G.R.-T., J.D.-C. 
and C.R.-E.; the project administration was carried out by R.R.-B., M.M.-F., G.R.-T., J.D.-C., C.V.-G. and O.A.; the writing-review and editing-was carried out by R.R.-B., C.H.C.-S., P.C.-G., C.V.-G., N.Y.H.-P., A.O.-G., L.L.-M., C.R.-E. and O.A.; and the supervision was by P.C.-G., M.M.-F., G.R.-T., J.D.-C., C.V.-G., N.Y.H.-P. and O.A. All authors have read and agreed to the published version of the manuscript.

Funding: This work was funded by the INCan and Laboratory of Personalized Medicine of the Thoracic Oncology Unit and the Fondo SS/IMSS/ISSSTE-CONACYT (grant number SALUD-2013-1-201336).

Institutional Review Board Statement: The study was conducted according to the guidelines of the Declaration of Helsinki and approved by the Institutional Review Board and Ethics Committee of the Instituto Nacional de Cancerología (INCan) (INCAN/CEI/224/13/CEI/847; S0008-2013-1-201336).

Informed Consent Statement: Informed consent was obtained from all subjects involved in the study.

Data Availability Statement: The microarray data presented in this study are available on GEO Accession number GSE176128. The sequencing data are available upon request to the corresponding author. The clinical data are not publicly available due to ethical institutional policies regarding patient confidentiality.

Acknowledgments: Rubén Rodríguez Bautista is a doctoral student from Programa de Doctorado en Ciencias Biomédicas, Universidad Nacional Autónoma de México (UNAM), and received fellowship (CVU 707316) from CONACYT. We want to thank all the patients who participated in this study and all the medical and nursing staff of the Instituto Nacional de Cancerologia (INCan) for their support. We appreciate the support of Raul Mojica from the Instituto Nacional de Medicina Genómica (INMEGEN) microarray core lab, Claudia H. C. Sánchez, Guadalupe M. Claudio and María de Lourdes P. Torres for their help.

Conflicts of Interest: Oscar Arrieta has received honoraria as an advisor, participated in speakers' bureau, and given expert opinions to Pfizer, AstraZeneca, Boehringer-Ingelheim, Roche, Lilly, and Bristol-Myers Squibb. All other authors declare no potential conflict of interest.

\section{References}

1. Lara-Medina, F.; Pérez-Sánchez, V.; Saavedra-Pérez, D.; Blake-Cerda, M.; Arce, C.; Motola-Kuba, D.; Villarreal-Garza, C.; González-Angulo, A.M.; Bargalló, E.; Aguilar, J.L.; et al. Triple-Negative Breast Cancer in Hispanic Patients. Cancer 2011, 117, 3658-3669. [CrossRef] [PubMed]

2. Rey-Vargas, L.; Sanabria-Salas, M.C.; Fejerman, L.; Serrano-Gomez, S.J. Risk Factors for Triple-Negative Breast Cancer among Latina Women. Cancer Epidemiol. Biomark. Prev. Publ. Am. Assoc. Cancer Res. Cosponsored Soc. Prev. Oncol. 2019, 28, 1771-1783. [CrossRef] [PubMed]

3. Burstein, M.D.; Tsimelzon, A.; Poage, G.M.; Covington, K.R.; Contreras, A.; Fuqua, S.A.W.; Savage, M.I.; Osborne, C.K.; Hilsenbeck, S.G.; Chang, J.C.; et al. Comprehensive Genomic Analysis Identifies Novel Subtypes and Targets of Triple-Negative Breast Cancer. Clin. Cancer Res. 2015, 21, 1688-1698. [CrossRef] [PubMed]

4. Lehmann, B.D.; Bauer, J.A.; Chen, X.; Sanders, M.E.; Chakravarthy, A.B.; Shyr, Y.; Pietenpol, J.A. Identification of Human Triple-Negative Breast Cancer Subtypes and Preclinical Models for Selection of Targeted Therapies. J. Clin. Investig. 2011, 121, 2750-2767. [CrossRef]

5. Wang, D.Y.; Jiang, Z.; Ben-David, Y.; Woodgett, J.R.; Zacksenhaus, E. Molecular Stratification within Triple-Negative Breast Cancer Subtypes. Sci. Rep. 2019, 9, 19107. [CrossRef]

6. Yousefi, H.; Yuan, J.; Keshavarz-Fathi, M.; Murphy, J.F.; Rezaei, N. Immunotherapy of Cancers Comes of Age. Expert Rev. Clin. Immunol. 2017, 13, 1001-1015. [CrossRef]

7. Disis, M.L.; Stanton, S.E. Triple-Negative Breast Cancer: Immune Modulation as the New Treatment Paradigm. Am. Soc. Clin. Oncol. Educ. Book 2015, 35, e25-e30. [CrossRef]

8. Ono, M.; Tsuda, H.; Shimizu, C.; Yamamoto, S.; Shibata, T.; Yamamoto, H.; Hirata, T.; Yonemori, K.; Ando, M.; Tamura, K.; et al. Tumor-Infiltrating Lymphocytes Are Correlated with Response to Neoadjuvant Chemotherapy in Triple-Negative Breast Cancer. Breast Cancer Res. Treat. 2012, 132, 793-805. [CrossRef]

9. Dieci, M.V.; Criscitiello, C.; Goubar, A.; Viale, G.; Conte, P.; Guarneri, V.; Ficarra, G.; Mathieu, M.C.; Delaloge, S.; Curigliano, G.; et al. Prognostic Value of Tumor-Infiltrating Lymphocytes on Residual Disease after Primary Chemotherapy for Triple-Negative Breast Cancer: A Retrospective Multicenter Study. Ann. Oncol. 2014, 25, 611-618. [CrossRef] [PubMed]

10. Du, Q.; Che, J.; Jiang, X.; Li, L.; Luo, X.; Li, Q. PD-L1 Acts as a Promising Immune Marker to Predict the Response to Neoadjuvant Chemotherapy in Breast Cancer Patients. Clin. Breast Cancer 2020, 20, e99-e111. [CrossRef] [PubMed]

11. Liu, S.; Lachapelle, J.; Leung, S.; Gao, D.; Foulkes, W.D.; Nielsen, T.O. CD8+ lymphocyte Infiltration Is an Independent Favorable Prognostic Indicator in Basal-like Breast Cancer. Breast Cancer Res. 2012, 14, 1-14. [CrossRef] [PubMed] 
12. Mahmoud, S.M.A.; Paish, E.C.; Powe, D.G.; Macmillan, R.D.; Grainge, M.J.; Lee, A.H.S.; Ellis, I.O.; Green, A.R. Tumor-Infiltrating CD8+ Lymphocytes Predict Clinical Outcome in Breast Cancer. J. Clin. Oncol. 2011, 29, 1949-1955. [CrossRef] [PubMed]

13. Gao, G.; Wang, Z.; Qu, X.; Zhang, Z. Prognostic Value of Tumor-Infiltrating Lymphocytes in Patients with Triple-Negative Breast Cancer: A Systematic Review and Meta-Analysis. BMC Cancer 2020, 20, 179. [CrossRef] [PubMed]

14. Miyashita, M.; Sasano, H.; Tamaki, K.; Chan, M.; Hirakawa, H.; Suzuki, A.; Tada, H.; Watanabe, G.; Nemoto, N.; Nakagawa, S.; et al. Tumor-Infiltrating CD8+ and FOXP3+ Lymphocytes in Triple-Negative Breast Cancer: Its Correlation with Pathological Complete Response to Neoadjuvant Chemotherapy. Breast Cancer Res. Treat. 2014, 148, 525-534. [CrossRef] [PubMed]

15. Schmid, P.; Rugo, H.S.; Adams, S.; Schneeweiss, A.; Barrios, C.H.; Iwata, H.; Diéras, V.; Henschel, V.; Molinero, L.; Chui, S.Y.; et al. Atezolizumab plus Nab-Paclitaxel as First-Line Treatment for Unresectable, Locally Advanced or Metastatic Triple-Negative Breast Cancer (IMpassion130): Updated Efficacy Results from a Randomised, Double-Blind, Placebo-Controlled, Phase 3 Trial. Lancet Oncol. 2020, 21, 44-59. [CrossRef]

16. Schmid, P.; Adams, S.; Rugo, H.S.; Schneeweiss, A.; Barrios, C.H.; Iwata, H.; Diéras, V.; Hegg, R.; Im, S.-A.; Shaw Wright, G.; et al. Atezolizumab and Nab-Paclitaxel in Advanced Triple-Negative Breast Cancer. N. Engl. J. Med. 2018, 379, 2108-2121. [CrossRef] [PubMed]

17. Cortes, J.; Cescon, D.W.; Rugo, H.S.; Nowecki, Z.; Im, S.A.; Yusof, M.M.; Gallardo, C.; Lipatov, O.; Barrios, C.H.; Holgado, E.; et al. Pembrolizumab plus Chemotherapy versus Placebo plus Chemotherapy for Previously Untreated Locally Recurrent Inoperable or Metastatic Triple-Negative Breast Cancer (KEYNOTE-355): A Randomised, Placebo-Controlled, Double-Blind, Phase 3 Clinical Trial. Lancet 2020, 396, 1817-1828. [CrossRef]

18. Schmid, P.; Cortes, J.; Pusztai, L.; McArthur, H.; Kümmel, S.; Bergh, J.; Denkert, C.; Park, Y.H.; Hui, R.; Harbeck, N.; et al. Pembrolizumab for Early Triple-Negative Breast Cancer. N. Engl. J. Med. 2020, 382, 810-821. [CrossRef]

19. Mittendorf, E.A.; Zhang, H.; Barrios, C.H.; Saji, S.; Jung, K.H.; Hegg, R.; Koehler, A.; Sohn, J.; Iwata, H.; Telli, M.L.; et al. Neoadjuvant Atezolizumab in Combination with Sequential Nab-Paclitaxel and Anthracycline-Based Chemotherapy versus Placebo and Chemotherapy in Patients with Early-Stage Triple-Negative Breast Cancer (IMpassion031): A Randomised, DoubleBlind, Phase 3 Trial. Lancet 2020, 396, 1090-1100. [CrossRef]

20. Stovgaard, E.S.; Dyhl-Polk, A.; Roslind, A.; Balslev, E.; Nielsen, D. PD-L1 Expression in Breast Cancer: Expression in Subtypes and Prognostic Significance: A Systematic Review. Breast Cancer Res. Treat. 2019, 174, 571-584. [CrossRef]

21. Mittendorf, E.A.; Philips, A.V.; Meric-Bernstam, F.; Qiao, N.; Wu, Y.; Harrington, S.; Su, X.; Wang, Y.; Gonzalez-Angulo, A.M.; Akcakanat, A.; et al. PD-L1 Expression in Triple-Negative Breast Cancer. Cancer Immunol. Res. 2014, 2, 361-370. [CrossRef]

22. Peng, Z.; Su, P.; Yang, Y.; Yao, X.; Zhang, Y.; Jin, F.; Yang, B. Identification of CTLA-4 Associated with Tumor Microenvironment and Competing Interactions in Triple Negative Breast Cancer by Co-Expression Network Analysis. J. Cancer 2020, 11, 6365-6375. [CrossRef]

23. Karn, T.; Jiang, T.; Hatzis, C.; Sänger, N.; El-Balat, A.; Rody, A.; Holtrich, U.; Becker, S.; Bianchini, G.; Pusztai, L. Association Between Genomic Metrics and Immune Infiltration in Triple-Negative Breast Cancer. JAMA Oncol. 2017, 3, 1707-1711. [CrossRef] [PubMed]

24. Allison, K.H.; Hammond, M.E.H.; Dowsett, M.; McKernin, S.E.; Carey, L.A.; Fitzgibbons, P.L.; Hayes, D.F.; Lakhani, S.R.; Chavez-MacGregor, M.; Perlmutter, J.; et al. Estrogen and Progesterone Receptor Testing in Breast Cancer: ASCO/CAP Guideline Update. J. Clin. Oncol. 2020, 38, 1346-1366. [CrossRef] [PubMed]

25. Irizarry, R.A.; Bolstad, B.M.; Collin, F.; Cope, L.M.; Hobbs, B.; Speed, T.P. Summaries of Affymetrix GeneChip Probe Level Data. Nucleic Acids Res. 2003, 31, e15. [CrossRef] [PubMed]

26. Chen, X.; Li, J.; Gray, W.H.; Lehmann, B.D.; Bauer, J.A.; Shyr, Y.; Pietenpol, J.A. TNBCtype: A Subtyping Tool for Triple-Negative Breast Cancer. Cancer Inform. 2012, 11, 147-156. [CrossRef] [PubMed]

27. Ritchie, M.E.; Phipson, B.; Wu, D.; Hu, Y.; Law, C.W.; Shi, W.; Smyth, G.K. Limma Powers Differential Expression Analyses for RNA-Sequencing and Microarray Studies. Nucleic Acids Res. 2015, 43, e47. [CrossRef] [PubMed]

28. Benjamini, Y.; Hochberg, Y. Controlling the False Discovery Rate: A Practical and Powerful Approach to Multiple Testing. J. R. Stat. Soc. Ser. B 1995, 57, 289-300. [CrossRef]

29. Babraham Bioinformatics-FastQC A Quality Control Tool for High Throughput Sequence Data. Available online: https: //www.bioinformatics.babraham.ac.uk/projects/fastqc/ (accessed on 12 November 2021).

30. Bolger, A.M.; Lohse, M.; Usadel, B. Trimmomatic: A Flexible Trimmer for Illumina Sequence Data. Bioinformatics 2014, 30, 2114-2120. [CrossRef] [PubMed]

31. McKenna, A.; Hanna, M.; Banks, E.; Sivachenko, A.; Cibulskis, K.; Kernytsky, A.; Garimella, K.; Altshuler, D.; Gabriel, S.; Daly, M.; et al. The Genome Analysis Toolkit: A MapReduce Framework for Analyzing next-Generation DNA Sequencing Data. Genome Res. 2010, 20, 1297-1303. [CrossRef] [PubMed]

32. Skidmore, Z.L.; Wagner, A.H.; Lesurf, R.; Campbell, K.M.; Kunisaki, J.; Griffith, O.L.; Griffith, M. GenVisR: Genomic Visualizations in R. Bioinformatics 2016, 32, 3012-3014. [CrossRef] [PubMed]

33. Emens, L.A.; Cruz, C.; Eder, J.P.; Braiteh, F.; Chung, C.; Tolaney, S.M.; Kuter, I.; Nanda, R.; Cassier, P.A.; Delord, J.P.; et al. Long-Term Clinical Outcomes and Biomarker Analyses of Atezolizumab Therapy for Patients with Metastatic Triple-Negative Breast Cancer: A Phase 1 Study. JAMA Oncol. 2019, 5, 74-82. [CrossRef] [PubMed] 
34. Miles, D.; Gligorov, J.; André, F.; Cameron, D.; Schneeweiss, A.; Barrios, C.; Xu, B.; Wardley, A.; Kaen, D.; Andrade, L.; et al. Primary Results from IMpassion131, a Double-Blind, Placebo-Controlled, Randomised Phase III Trial of First-Line Paclitaxel with or without Atezolizumab for Unresectable Locally Advanced/Metastatic Triple-Negative Breast Cancer. Ann. Oncol. 2021, 32, 994-1004. [CrossRef] [PubMed]

35. Roche-Roche Provides Update on Tecentriq US Indication for PD-L1-Positive, Metastatic Triple-Negative Breast Cancer. Available online: https:/ /www.roche.com/media/releases/med-cor-2021-08-27.htm (accessed on 16 November 2021).

36. Zhao, S.; Ma, D.; Xiao, Y.; Li, X.; Ma, J.; Zhang, H.; Xu, X.; Lv, H.; Jiang, W.; Yang, W.; et al. Molecular Subtyping of Triple-Negative Breast Cancers by Immunohistochemistry: Molecular Basis and Clinical Relevance. Oncologist 2020, 25, e1481. [CrossRef]

37. Santonja, A.; Sánchez-Muñoz, A.; Lluch, A.; Chica-Parrado, M.R.; Albanell, J.; Chacón, J.I.; Antolín, S.; Jerez, J.M.; de la Haba, J.; de Luque, V.; et al. Triple Negative Breast Cancer Subtypes and Pathologic Complete Response Rate to Neoadjuvant Chemotherapy. Oncotarget 2018, 9, 26406. [CrossRef]

38. Funakoshi, Y.; Wang, Y.; Semba, T.; Masuda, H.; Hout, D.; Ueno, N.T.; Wang, X. Comparison of Molecular Profile in Triple-Negative Inflammatory and Non-Inflammatory Breast Cancer Not of Mesenchymal Stem-like Subtype. PLoS ONE 2019, 14, e0222336. [CrossRef] [PubMed]

39. Bareche, Y.; Venet, D.; Ignatiadis, M.; Aftimos, P.; Piccart, M.; Rothe, F.; Sotiriou, C. Unravelling Triple-Negative Breast Cancer Molecular Heterogeneity Using an Integrative Multiomic Analysis. Ann. Oncol. 2018, 29, 895-902. [CrossRef] [PubMed]

40. Li, X.; Xiang, Y.; Li, F.; Yin, C.; Li, B.; Ke, X. WNT / $\beta$-Catenin Signaling Pathway Regulating T Cell-Inflammation in the Tumor Microenvironment. Front. Immunol. 2019, 10, 2293. [CrossRef]

41. Wang, B.; Tian, T.; Kalland, K.H.; Ke, X.; Qu, Y. Targeting Wnt/ $\beta$-Catenin Signaling for Cancer Immunotherapy. Trends Pharmacol. Sci. 2018, 39, 648-658. [CrossRef] [PubMed]

42. Yu, Q.C.; Verheyen, E.M.; Zeng, Y.A. Mammary Development and Breast Cancer: A Wnt Perspective. Cancers 2016, 8, 65. [CrossRef] [PubMed]

43. Katoh, M. Canonical and Non-Canonical WNT Signaling in Cancer Stem Cells and Their Niches: Cellular Heterogeneity, Omics Reprogramming, Targeted Therapy and Tumor Plasticity (Review). Int. J. Oncol. 2017, 51, 1357-1369. [CrossRef] [PubMed]

44. Khramtsov, A.I.; Khramtsova, G.F.; Tretiakova, M.; Huo, D.; Olopade, O.I.; Goss, K.H. Wnt/Beta-Catenin Pathway Activation Is Enriched in Basal-like Breast Cancers and Predicts Poor Outcome. Am. J. Pathol. 2010, 176, 2911-2920. [CrossRef]

45. Kwee, S.A.; Tiirikainen, M. Beta-Catenin Activation and Immunotherapy Resistance in Hepatocellular Carcinoma: Mechanisms and Biomarkers. Hepatoma Res. 2021, 7, 8. [CrossRef]

46. Morin, P.J.; Kinzler, K.W.; Sparks, A.B. $\beta$-Catenin Mutations: Insights into the APC Pathway and the Power of Genetics. Cancer Res. 2016, 76, 5587-5589. [CrossRef] [PubMed]

47. Rodríguez Bautista, R.; Ortega Gómez, A.; Hidalgo Miranda, A.; Zentella Dehesa, A.; Villarreal-Garza, C.; Ávila-Moreno, F.; Arrieta, O. Long Non-Coding RNAs: Implications in Targeted Diagnoses, Prognosis, and Improved Therapeutic Strategies in Human Non- and Triple-Negative Breast Cancer. Clin. Epigenet. 2018, 10, 88. [CrossRef] [PubMed]

48. Beltrán-Anaya, F.O.; Romero-Córdoba, S.; Rebollar-Vega, R.; Arrieta, O.; Bautista-Piña, V.; Dominguez-Reyes, C.; Villegas-Carlos, F.; Tenorio-Torres, A.; Alfaro-Riuz, L.; Jiménez-Morales, S.; et al. Expression of Long Non-Coding RNA ENSG00000226738 (LncKLHDC7B) Is Enriched in the Immunomodulatory Triple-Negative Breast Cancer Subtype and Its Alteration Promotes Cell Migration, Invasion, and Resistance to Cell Death. Mol. Oncol. 2019, 13, 909-927. [CrossRef]

49. Koliaraki, V.; Prados, A.; Armaka, M.; Kollias, G. The Mesenchymal Context in Inflammation, Immunity and Cancer. Nat. Immunol. 2020, 21, 974-982. [CrossRef]

50. Li, H.; Mu, Q.; Zhang, G.; Shen, Z.; Zhang, Y.; Bai, J.; Zhang, L.; Zhou, D.; Zheng, Q.; Shi, L.; et al. Linc00426 Accelerates Lung Adenocarcinoma Progression by Regulating MiR-455-5p as a Molecular Sponge. Cell Death Dis. 2020, 11, 1051. [CrossRef] [PubMed]

51. Chen, J.; Li, P.; Chen, Z.; Wang, S.; Tang, S.; Chen, X.; Chen, Z.; Zhou, J. Elevated LINC01550 Induces the Apoptosis and Cell Cycle Arrest of Melanoma. Med Oncol. 2021, 38, 32. [CrossRef] [PubMed]

52. Fan, H.; Yuan, J.; Li, X.; Ma, Y.; Wang, X.; Xu, B.; Li, X. LncRNA LINC00173 Enhances Triple-Negative Breast Cancer Progression by Suppressing MiR-490-3p Expression. Biomed. Pharmacother. 2020, 125, 109987. [CrossRef] [PubMed]

53. Zhang, Y.; Li, Y.; Wang, Q.; Zhang, X.; Wang, D.; Tang, H.C.; Meng, X.; Ding, X. Identification of an IncRNA-MiRNA-MRNA Interaction Mechanism in Breast Cancer Based on Bioinformatic Analysis. Mol. Med. Rep. 2017, 16, 5113-5120. [CrossRef] [PubMed]

54. Chen, Y.; Qiu, F.; Huang, L.; Liu, W.; Li, L.; Ji, C.; Zeng, X.; Qiao, L.; Liu, M.; Gong, X. Long Non-Coding RNA LINC00312 Regulates Breast Cancer Progression through the MiR-9/CDH1 Axis. Mol. Med. Rep. 2020, 21, 1296-1303. [CrossRef] [PubMed]

55. Li, W.; Xu, C.; Guo, J.; Liu, K.; Hu, Y.; Wu, D.; Fang, H.; Zou, Y.; Wei, Z.; Wang, Z.; et al. Cis- and Trans-Acting Expression Quantitative Trait Loci of Long Non-Coding RNA in 2549 Cancers With Potential Clinical and Therapeutic Implications. Front. Oncol. 2020, 10, 2279. [CrossRef] 
56. Yang, Q.; Tang, Y.; Tang, C.; Cong, H.; Wang, X.; Shen, X.; Ju, S. Diminished LINC00173 Expression Induced MiR-182-5p Accumulation Promotes Cell Proliferation, Migration and Apoptosis Inhibition via AGER/NF-KB Pathway in Non-Small-Cell Lung Cancer. Am. J. Transl. Res. 2019, 11, 4248-4262. [PubMed]

57. Hu, W.; Wang, Y.; Fang, Z.; He, W.; Li, S. Integrated Characterization of LncRNA-Immune Interactions in Prostate Cancer. Front. Cell Dev. Biol. 2021, 9, 271. [CrossRef] [PubMed]

58. Peng, Z.; Wang, J.; Shan, B.; Li, B.; Peng, W.; Dong, Y.; Shi, W.; Zhao, W.; He, D.; Duan, M.; et al. The Long Noncoding RNA LINC00312 Induces Lung Adenocarcinoma Migration and Vasculogenic Mimicry through Directly Binding YBX1. Mol. Cancer 2018, 17, 167. [CrossRef] [PubMed]

59. Sun, X.-J.; Wang, Q.; Guo, B.; Liu, X.-Y.; Wang, B. Identification of Skin-Related LncRNAs as Potential Biomarkers That Involved in Wnt Pathways in Keloids. Oncotarget 2017, 8, 34236-34244. [CrossRef]

60. Li, Q.; Chen, X.; Chen, L.; Yan, H.; Li, J. LINC00173 Promotes the Apoptosis of Hypertrophic Scar Fibroblasts through Increasing $\beta$-Catenin Expression. Mol. Cell. Biochem. 2020, 476, 1005-1014. [CrossRef] [PubMed]

61. Liu, H.; Zhang, L.; Ding, X.; Sui, X. LINC00861 Inhibits the Progression of Cervical Cancer Cells by Functioning as a CeRNA for MiR-513b-5p and Regulating the PTEN/AKT/MTOR Signaling Pathway. Mol. Med. Rep. 2021, 23, 1. [CrossRef]

62. Guo, Z.; Wang, Y.H.; Xu, H.; Yuan, C.S.; Zhou, H.H.; Huang, W.H.; Wang, H.; Zhang, W. LncRNA Linc00312 Suppresses Radiotherapy Resistance by Targeting DNA-PKcs and Impairing DNA Damage Repair in Nasopharyngeal Carcinoma. Cell Death Dis. 2021, 12, 69. [CrossRef] [PubMed]

63. Yu, Y.; Wu, J.; Wang, Y.; Zhao, T.; Ma, B.; Liu, Y.; Fang, W.; Zhu, W.G.; Zhang, H. Kindlin 2 Forms a Transcriptional Complex with $\beta$-Catenin and TCF4 to Enhance Wnt Signalling. EMBO Rep. 2012, 13, 750-758. [CrossRef]

64. Genovese, G.; Ghosh, P.; Li, H.; Rettino, A.; Sioletic, S.; Cittadini, A.; Sgambato, A. The Tumor Suppressor HINT1 Regulates MITF and $\beta$-Catenin Transcriptional Activity in Melanoma Cells. Cell Cycle (Georgetown, Tex.) 2012, 11, 2206-2215. [CrossRef] [PubMed]

65. Satow, R.; Shitashige, M.; Jigami, T.; Fukami, K.; Honda, K.; Kitabayashi, I.; Yamada, T. $\beta$-Catenin Inhibits Promyelocytic Leukemia Protein Tumor Suppressor Function in Colorectal Cancer Cells. Gastroenterology 2012, 142, 572-581. [CrossRef]

66. Fiset, A.; Xu, E.; Bergeron, S.; Marette, A.; Pelletier, G.; Siminovitch, K.A.; Olivier, M.; Beauchemin, N.; Faure, R.L. Compartmentalized CDK2 Is Connected with SHP-1 and $\beta$-Catenin and Regulates Insulin Internalization. Cell. Signal. 2011, 23, 911-919. [CrossRef] [PubMed]

67. Li, H.; Ray, G.; Yoo, B.H.; Erdogan, M.; Rosen, K.V. Down-Regulation of Death-Associated Protein Kinase-2 Is Required for Beta-Catenin-Induced Anoikis Resistance of Malignant Epithelial Cells. J. Biol. Chem. 2009, 284, 2012-2022. [CrossRef] [PubMed]

68. Bahmanyar, S.; Kaplan, D.D.; DeLuca, J.G.; Giddings, T.H.; O’Toole, E.T.; Winey, M.; Salmon, E.D.; Casey, P.J.; Nelson, W.J.; Barth A.I.M. Beta-Catenin Is a Nek2 Substrate Involved in Centrosome Separation. Genes Dev. 2008, 22, 91-105. [CrossRef] [PubMed]

69. Weiske, J.; Albring, K.F.; Huber, O. The Tumor Suppressor Fhit Acts as a Repressor of Beta-Catenin Transcriptional Activity. Proc. Natl. Acad. Sci. USA 2007, 104, 20344-20349. [CrossRef]

70. Lillehoj, E.P.; Lu, W.; Kiser, T.; Goldblum, S.E.; Kim, K.C. MUC1 Inhibits Cell Proliferation by a Beta-Catenin-Dependent Mechanism. Biochim. Biophys. Acta 2007, 1773, 1028-1038. [CrossRef]

71. Liu, F.; Lang, R.; Zhao, J.; Zhang, X.; Pringle, G.A.; Fan, Y.; Yin, D.; Gu, F.; Yao, Z.; Fu, L. CD8 ${ }^{+}$Cytotoxic T Cell and FOXP3 ${ }^{+}$ Regulatory T Cell Infiltration in Relation to Breast Cancer Survival and Molecular Subtypes. Breast Cancer Res. Treat. 2011, 130, 645-655. [CrossRef] [PubMed]

72. Chen, W.J.; Wahl, S.M. TGF-Beta: The Missing Link in CD4+ CD25+ Regulatory T Cell-Mediated Immunosuppression. Cytokine Growth Factor Rev. 2003, 14, 85-89. [CrossRef]

73. Liu, F.; Li, Y.; Ren, M.; Zhang, X.; Guo, X.; Lang, R.; Gu, F.; Fu, L. Peritumoral FOXP3+ Regulatory T Cell Is Sensitive to Chemotherapy While Intratumoral FOXP3+ Regulatory T Cell Is Prognostic Predictor of Breast Cancer Patients. Breast Cancer Res. Treat. 2012, 135, 459-467. [CrossRef] [PubMed]

74. Yeong, J.; Thike, A.A.; Lim, J.C.T.; Lee, B.; Li, H.; Wong, S.-C.; Hue, S.S.S.; Tan, P.H.; Iqbal, J. Higher Densities of Foxp3 + Regulatory T Cells Are Associated with Better Prognosis in Triple-Negative Breast Cancer. Breast Cancer Res. Treat. 2017, 163, 21-35. [CrossRef] [PubMed]

75. Oldenhove, G.; de Heusch, M.; Urbain-Vansanten, G.; Urbain, J.; Maliszewski, C.; Leo, O.; Moser, M. CD4+ CD25+ Regulatory T Cells Control T Helper Cell Type 1 Responses to Foreign Antigens Induced by Mature Dendritic Cells In Vivo. J. Exp. Med. 2003, 198, 259. [CrossRef] [PubMed]

76. Lee, Y.K.; Turner, H.; Maynard, C.L.; Oliver, J.R.; Chen, D.; Elson, C.O.; Weaver, C.T. Late Developmental Plasticity in the T Helper 17 Lineage. Immunity 2009, 30, 92. [CrossRef] [PubMed]

77. Ren, X.; Wu, H.; Lu, J.; Zhang, Y.; Luo, Y.; Xu, Q.; Shen, S.; Liang, Z. PD1 Protein Expression in Tumor Infiltrated Lymphocytes Rather than PDL1 in Tumor Cells Predicts Survival in Triple-Negative Breast Cancer. Cancer Biol. Ther. 2018, 19, 373-380. [CrossRef]

78. Beckers, R.K.; Selinger, C.I.; Vilain, R.; Madore, J.; Wilmott, J.S.; Harvey, K.; Holliday, A.; Cooper, C.L.; Robbins, E.; Gillett, D.; et al. Programmed Death Ligand 1 Expression in Triple-Negative Breast Cancer Is Associated with Tumour-Infiltrating Lymphocytes and Improved Outcome. Histopathology 2016, 69, 25-34. [CrossRef] [PubMed] 
79. $\quad$ Emens, L.A.; Goldstein, L.D.; Schmid, P.; Rugo, H.S.; Adams, S.; Barrios, C.H.; Schneeweiss, A.; Dieras, V.; Iwata, H.; Chang, C.-W.; et al. The Tumor Microenvironment (TME) and Atezolizumab + Nab-Paclitaxel (A+nP) Activity in Metastatic Triple-Negative Breast Cancer (MTNBC): IMpassion130. J. Clin. Oncol. 2021, 39, 1006. [CrossRef]

80. Hassel, J.C.; Heinzerling, L.; Aberle, J.; Bähr, O.; Eigentler, T.K.; Grimm, M.O.; Grünwald, V.; Leipe, J.; Reinmuth, N.; Tietze, J.K.; et al. Combined Immune Checkpoint Blockade (Anti-PD-1/Anti-CTLA-4): Evaluation and Management of Adverse Drug Reactions. Cancer Treat. Rev. 2017, 57, 36-49. [CrossRef] [PubMed]

81. Sznol, M.; Ferrucci, P.F.; Hogg, D.; Atkins, M.B.; Wolter, P.; Guidoboni, M.; Lebbé, C.; Kirkwood, J.M.; Schachter, J.; Daniels, G.A.; et al. Pooled Analysis Safety Profile of Nivolumab and Ipilimumab Combination Therapy in Patients With Advanced Melanoma. J. Clin. Oncol. 2017, 35, 3815-3822. [CrossRef] 